\title{
Lógicas de ocupación y acceso al suelo en procesos de desarrollo residencial expansivo. El caso de la periferia del partido de La Plata [2003-2016]
}

María Luciana Giglio

Arquitecta. Doctora en Estudios Urbanos del ICO-UNGS. Becaria posdoctoral CONICET. Instituto de Investigaciones y Políticas del Ambiente Construido (IIPAC), FAU, UNLP.

luciana.giglio@gmail.com

Rocío Rodríguez Tarducci

Arquitecta. Doctoranda en Geografía, FaHCE-UNLP. Becaria doctoral CONICET. Instituto de Investigaciones y Políticas del Ambiente Construido (IIPAC), FAU, UNLP.

rociotarducci@gmail.com

Daniela Cortizo

Arquitecta. Doctoranda en Geografía, FaHCE, UNLP. Becaria doctoral CONICET. Instituto de Investigaciones y Políticas del Ambiente Construido (IIPAC), FAU, UNLP.

cortizodaniela@gmail.com

Julieta Frediani

Dra. en Geografía, FaHCE, UNLP. Investigadora adjunta del CONICET. Instituto de Investigaciones y Políticas del Ambiente Construido (IIPAC), FAU, UNLP.

jfrediani@yahoo.com

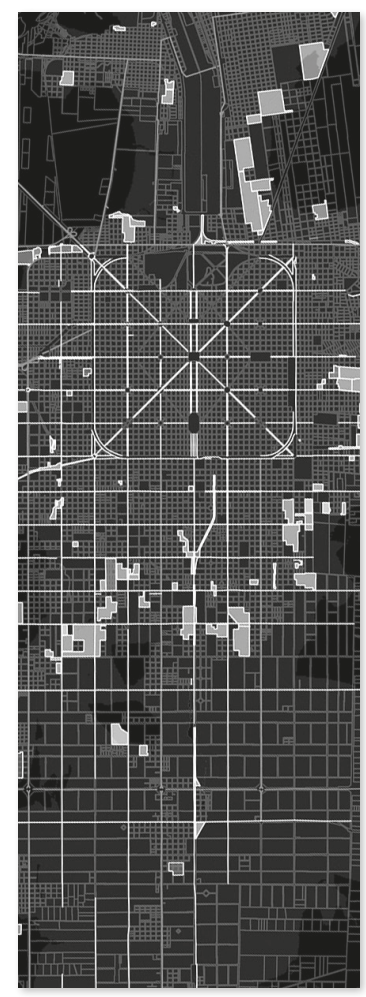




\section{Lógicas de ocupación y acceso al suelo en procesos de desarrollo residencial expansivo. El caso de la periferia del partido de La Plata [2003-2016)}

\section{Resumen}

En las últimas décadas se ha intensificado el proceso de urbanización en la Argentina, generalmente a través de la expansión de la mancha urbana y, por lo general, con pocas herramientas de planificación que orientaran u organizaran dicho proceso. El presente trabajo propone analizar las lógicas de ocupación residencial desarrolladas por diferentes actores en la periferia del partido de La Plata, en el contexto de una expansión creciente del parque habitacional. Para dicho análisis se consideraron las siguientes variables: (1) el contexto socioeconómico, (2) la normativa de usos de suelo, (3) las políticas públicas de vivienda, (4) la localización de los nuevos barrios y (5) el grado de consolidación. De esta forma, se busca dar cuenta de la relación entre los procesos de expansión urbana, la problemática del acceso al suelo, formal o informalmente, y la dificultad de acceder a un hábitat digno por parte de la población.

\section{Palabras clave}

Expansión urbana; lógicas de ocupación; acceso al suelo; periferia.

\section{Logic of occupation and access to the soil in processes of expansive residential development. The case of the periphery of the party of La Plata [2003-2016)}

\begin{abstract}
In the last decades the urbanization process in Argentina has intensified, generally through the sprawl of the urban stain and, in general, with few planning tools to guide or organize such a process. This paper proposes to analyze the logics of residential occupation developed by different actors in the periphery of the La Plata party, in the context of a growing expansion of the housing stock. For this analysis, the following variables were considered: (1) the socioeconomic context, (2) the land use regulations, (3) the public housing policies, (4) the location of the new neighborhoods and (5) the consolidation degree. In this way, it seeks to account for the relationship between urban sprawl processes, the problem of access to land, formally or informally, and the population's difficulty in accessing a decent habitat.
\end{abstract}

\section{Keywords}

Urban sprawl; Occupation logics; access to the soil; periphery.

\section{Logicas de ocupação e acesso ao solo em processos de desenvolvimento residencial expansivos. 0 caso da periferia do partido do La Plata}

\begin{abstract}
Resumo
Nas últimas décadas, o processo de urbanização na Argentina se intensificou, geralmente através da expansão da mancha urbana e, em geral, com poucas ferramentas de planejamento para orientar ou organizar esse processo. O presente trabalho propõe analisar as logicas de ocupação residencial desenvolvidas por diferentes atores na periferia do partido de La Plata, no contexto de uma crescente expansão do estoque habitacional. Para esta análise, foram consideradas as seguintes variáveis: (1) o contexto socioeconômico, (2) os regulamentos de uso do solo, (3) as políticas públicas de moradia, (4) a localização dos novos bairros e (5) o grau de consolidação. Dessa forma, busca-se explicar a relação entre os processos de expansão urbana, o problema do acesso à terra, formal ou informalmente, e a dificuldade de acessar um habitat decente pela população.

\section{Palavras chave}

Expansão urbana; logicas de ocupação; acesso ao solo; periferia.
\end{abstract}




\section{Introducción}

El modelo agroexportador y la migración europea de finales del s. XIX fueron los impulsores del proceso de urbanización en la Argentina. En el año 2001 el porcentaje de población en las ciudades había trepado al 89,5\%, y actualmente se estima en el 94 \% (Oporto, Aguilar y Blanco, 2011). De la mano de la urbanización y el desarrollo tecnológico devinieron nuevas problemáticas: la segregación, los conflictos por el acceso a la tierra, la vivienda y los servicios, la congestión en la movilidad diaria y la conflictividad ambiental, entre otras. Varias de estas problemáticas están vinculadas con el desarrollo de modelos urbanos expansivos, caracterizados por bajas densidades, alta dispersión y discontinuidades en relación con la trama urbana más consolidada.

Diversos estudios dan cuenta de la generalización de este tipo de crecimiento a nivel mundial, y advierten sobre el creciente desfasaje en la relación población-superficie urbanizada. El estudio de Argentina urbana (OроRто eт ÁL., 2011) indica que entre los años 2000 y 2030 la población urbana de la Argentina podría aumentar un 72 \%; la superficie urbana, en cambio, alcanzaría un crecimiento del 175 \% (más del doble). Los datos proporcionados por el Atlas de Crecimiento Urbano (CIPUV, 2013), que cuantifica la extensión de las ciudades argentinas entre los años 1990 y 2010, confirman dicha tendencia y anuncian que las áreas urbanas se están extendiendo anualmente a razón de una superficie equivalente al territorio de la Capital Federal $\left(200 \mathrm{~km}^{2} / \mathrm{año}\right)$.

En los últimos veinte años, el partido de La Plata aumentó un $21 \%$ su población, pero su superficie urbana creció un 127 \%, cinco veces más. Dicho crecimiento expansivo fue ocasionado, entre otras cosas, por (a) la especulación del sector inmobiliario sobre el precio del suelo urbano, y, por consiguiente, la dificultad de tener acceso a un terreno en las áreas centrales; (b) la implementación de políticas públicas para el acceso a la vivienda que no garantizaron el acceso al suelo urbano en áreas centrales y/o con servicios. En resumen, la falta de planificación, de seguimiento y la presencia de instrumentos de ordenamiento urbano ineficientes permitieron el desarrollo de un modelo de crecimiento fragmentado, en términos tanto espaciales como sociales.

El presente trabajo propone analizar las lógicas de ocupación residencial desarrolladas por diferentes actores en la periferia del partido de La Plata, en el contexto de una expansión 
creciente del parque habitacional, y determinar cómo se insertaron dichas lógicas en el territorio. Para poder indagar sobre dichos procesos, se consideraron las siguientes variables: (1) el contexto socioeconómico, (2) las normativas de usos de suelo vigentes, (3) las políticas públicas de vivienda implementadas, (4) la localización de los nuevos barrios correspondientes a cada período (formales e informales) y (5) el grado de consolidación del área donde se insertaron dichos barrios.

Para poder desarrollar el análisis propuesto, el artículo se estructura en cuatro apartados. El primer apartado establece, por un lado, el marco conceptual sobre las lógicas de los actores que se ponen en juego en la dinámica del mercado de suelo y, por otro lado, presenta el caso de estudio de la periferia del partido de La Plata. El segundo apartado desarrolla la propuesta metodológica. El tercer apartado expone el análisis de las lógicas de ocupación residencial en la periferia de La Plata. Dicho análisis se divide en dos cortes temporales: el primero en relación con el Plan Federal (2003-2012) y el segundo en relación con el programa de financiamiento de acceso a la vivienda ProCreAr (2012-2016). Por último, en el cuarto apartado, se enuncian unas breves reflexiones respecto de las observaciones desarrolladas a lo largo del trabajo.

\section{El mercado de suelo como promotor de la expansión urbana}

El crecimiento urbano y la desigualdad social en las ciudades argentinas están vinculados directamente con las prácticas de producción del suelo urbano y el rol determinante del mercado inmobiliario en el acceso al suelo y la vivienda. La segregación socio-espacial derivada de dichos procesos plantea la necesidad de analizar las consecuencias de un desarrollo urbano no planificado.

En lo que respecta al mercado de suelo y las lógicas que lo configuran, Pírez (1995) argumenta que en la producción, el consumo y la gestión del espacio urbano se pueden reconocer tres tipos de lógicas: (a) la lógica de obtención de ganancia que caracteriza a los sectores productivo, asalariado, inmobiliario, industrial y empresarial; (b) la lógica política que guía el accionar del Estado en sus distintos niveles y (c) la lógica de necesidad que desarrollan actores predominantemente por fuera del mercado y de las políticas públicas: habitantes que demandan viviendas, grupos barriales, ONG, etc. Varios autores coinciden en cómo las diferentes lógicas e intereses contribuyen a la conformación de una ciudad con características contrapuestas y segregadas. 
Por su parte, AвRAmo (2012) describe a las ciudades latinoamericanas como ciudades comfusas, producto del encuentro entre las diferentes lógicas de acceso al suelo. Desde este enfoque se advierte que el funcionamiento del mercado formal produce un tipo de ciudad compacta, por la densidad de las edificaciones que propone, y difusa a la vez, por la expulsión de hogares más pobres a periferias alejadas donde el acceso al suelo les sea posible. A la vez, el funcionamiento del mercado informal del suelo también produce una ciudad popular difusa por su localización alejada de las áreas centrales dentro del territorio, y compacta, a la vez, por el hacinamiento que se produce en los asentamientos, o por la búsqueda de inserción dentro de terrenos vacantes o intersticios que faciliten el acceso a las centralidades y el abastecimiento de servicios.

RoLNIK (2008) habla de un proceso de producción dual marcado por la implementación de la normativa urbana. Por un lado, se produce una ciudad que cumple con la norma, la cual responde a una lógica económica de negocio sobre el valor del suelo y que, en consecuencia, permite el acceso de una parte de la población a sectores de la ciudad próximos a las centralidades con servicios y equipamientos básicos. Por otro lado, existe una ciudad, por lo general mucho mayor que la anterior, que es autoproducida por su población, siguiendo no solo una lógica económica diferente de la del mercado formal, sino también una lógica cultural y espacial determinadas. Dichas formas de producción comparten un mismo territorio, pero las mejores áreas de la ciudad, las más aptas para urbanizar, son reservadas para los mercados de estratos socioeconómicos medio-altos, lo que excluye del acceso a suelo bien ubicado a todos los demás mercados "informales". Dicho bloqueo deja dos alternativas de inserción en el territorio para los sectores populares: en los intersticios del área central, que el mercado formal no puede ocupar por razones ambientales o de seguridad, o bien por fuera de los límites de ese mercado, en periferias alejadas de los centros urbanos.

Otra lógica en juego es la del Estado, la cual resulta contradictoria por momentos, ya que son las propias políticas urbanas las que generan exclusión. En este sentido, es posible afirmar que la política de subsidio habitacional siempre tuvo como primer objetivo garantizar el acceso a una vivienda (no a la ciudad). Dicho enfoque no representa una comprensión superadora de la problemática habitacional, que la propuesta por el mercado inmobiliario. La segregación residencial hacia la periferia urbana se convierte así en una constante en los resultados de dichas políticas (Baer y Kauw, 2016; Brain y Sabatini, 2006; Del Río, 2011). 
Los problemas se extienden más allá del acceso al suelo para vivienda, pues también los demás usos que la complementan tienen cada vez más dificultades de acceso al suelo bien ubicado y servido. Los usos con menores posibilidades de competir en el mercado de suelo tienen que conformarse con las peores ubicaciones, como son los usos públicos y los que cumplen una función ecológica. Como señala Morales-Schechinger (2005), los efectos de dicho accionar son, en términos urbanos, el crecimiento disperso residencial, monofuncional y sin infraestructuras de las áreas metropolitanas; en términos sociales, la segregación espacial cada vez más agravada en las ciudades. La desregulación del suelo al servicio de una lógica mercantil acrecentó la distribución inadecuada e injusta en los usos del suelo, y alimenta la distribución inequitativa de oportunidades para la mayoría de la población.

Acompañando las reflexiones de RoLnIK (2008), resulta clave comprender que el problema no es la falta de la normativa y de planificación, sino la existencia de una normativa excluyente y concentradora de renta, que ha diseñado en nuestras ciudades la expansión de la informalidad. La ilegalidad, irregularidad e informalidad son las estrategias adoptadas por los asentamientos para poder acceder a los mercados de suelo en las ciudades de América Latina (AвRAmo, 2008; Sabatini \& SmolKa, 2001). Sin embargo, la falta de servicios y las malas condiciones de accesibilidad de estos barrios han sido un factor adicional de empobrecimiento para estas familias. La segregación impuesta por la lógica del mercado de suelo, según la cual la vivienda se considera mercancía, niega de esta forma el derecho a una ciudadanía plena (LeFebvre, GonZÁlez-Pueyo y Gaviria, 1969).

\section{El cuadrado perfecto y la periferia imperfecta: el caso del partido de La Plata}

Desde fines de los años 80 se observa en la región un notable cambio en la morfología urbana, la cual se ha desbordado de los tejidos originales hacia la periferia (figura 1). Dicho avance urbano genera no solo la pérdida de tierras productivas, sino también nuevas formas de fragmentación socio-espacial con espacios cada vez más estratificados sobre la base de una estructura socio-económica desigual. La dinámica expansiva, a su vez, produce una alteración en los patrones de comportamiento de los actores involucrados en los procesos de crecimiento: el Estado, los agentes inmobiliarios, las empresas y, fundamentalmente, los habitantes de las áreas en transformación, quienes adoptan determinadas estrategias de acuerdo con sus lógicas e intereses dominantes (Frediani, 2006). 


\section{Lógicas de ocupación y acceso al suelo en procesos de desarrollo residencial expansivo.}

El caso de la periferia del partido de La Plata [2003-2016]

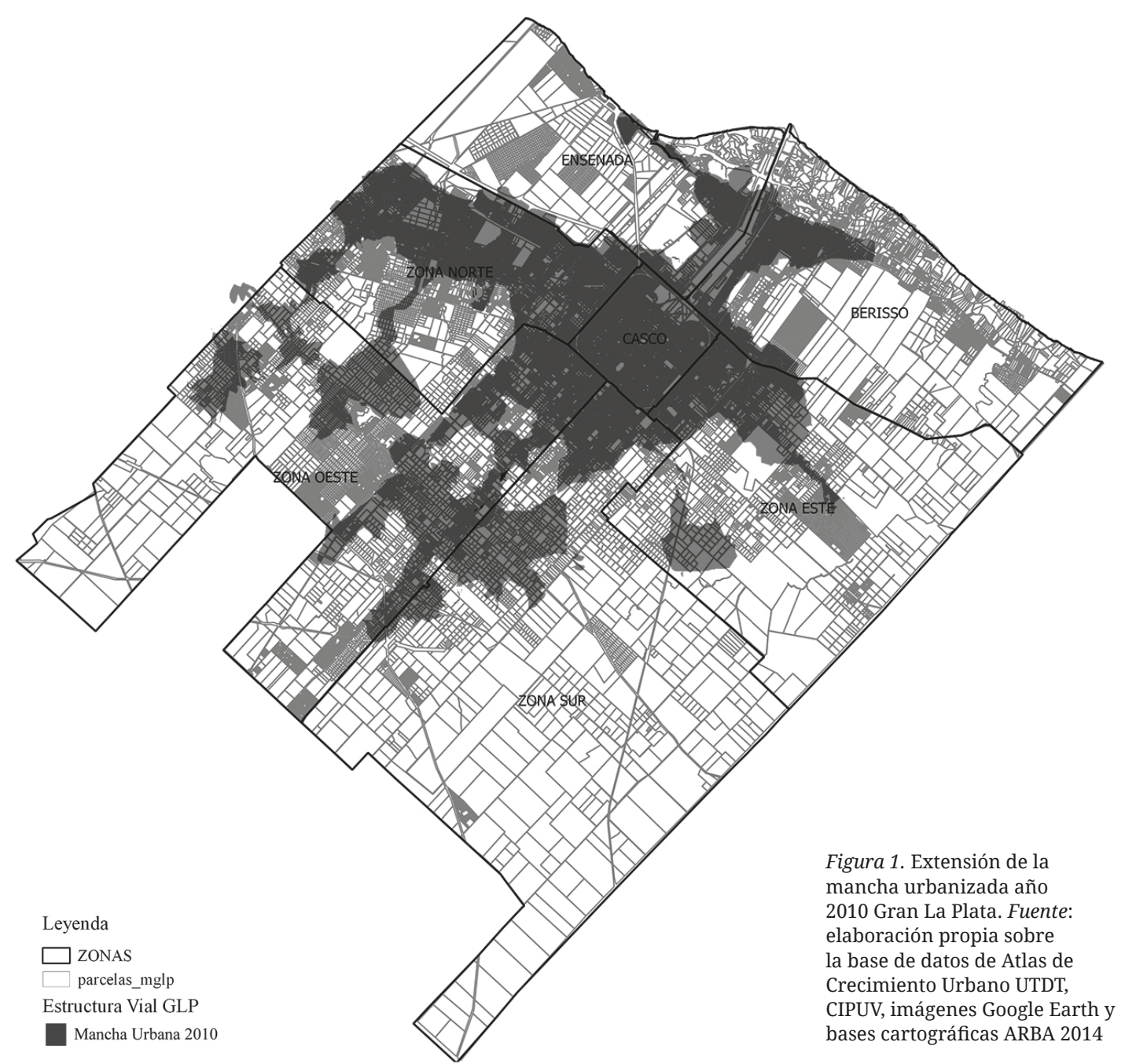


Los datos que arroja el último censo nacional (INDEC, 2010) muestran que en el partido de La Plata reside el 4,2 \% de la población de la provincia de Buenos Aires. Actualmente residen en el partido 649.613 habitantes, 75.244 más que los registrados en el censo anterior (INDEC, 2001). Es decir que la población creció un 13,1 \% en nueve años. Sin embargo, la cantidad de habitantes por vivienda disminuyó de 3,3 personas por vivienda en 2001 a 2,5 en 2010. Los datos censales indican un aumento del $51 \%$ del parque habitacional entre 2001 y 2010 (tabla 1), lo que explica en parte la reducción del índice general de ocupación. A su vez, se puede observar que en el mismo período la superficie urbana del partido creció un 57.54 \% (CIPUV, 2013), tres veces más que el crecimiento de la población (tabla 2). Estos dos factores indican, por un lado, una sobreproducción de vivienda en relación con la cantidad de población residente en el partido y, por otro lado, una expansión en la localización del nuevo parque habitacional.

\section{Tabla I}

Variación de Población, Viviendas y Hab./Vivienda del partido de La Plata, años 2001-2010

\begin{tabular}{lrrr}
\hline Partido de La Plata & 2001 & 2010 & Variación \% \\
\hline Población & 574.369 & 649.613 & 13,1 \\
\hline Viviendas & 172.140 & 259.352 & 50,7 \\
\hline Hab./Vivienda & 3,34 & 2,50 & -- \\
\hline
\end{tabular}

Fuente: elaboración propia sobre la base de datos de Censos INDEC 2001-2010

Tabla II

Crecimiento del área construida urbana, suburbana y rural del partido de La Plata, años 2000-2010

\begin{tabular}{lrrr}
\hline Área Construida (ha) & 2000 & 2010 & Variación \% \\
\hline Urbana & 7815,8 & $11.172,8$ & 43,0 \\
\hline Suburbana & 2525,1 & 5221 & 106,8 \\
\hline Rural & 422,5 & 563,1 & 33,3 \\
TOTAL & $\mathbf{1 0 . 7 6 3 , 4}$ & $\mathbf{1 6 . 9 5 6 , 9}$ & $\mathbf{5 7 , 5}$ \\
\hline
\end{tabular}

Fuente: elaboración propia sobre la base de datos del Atlas de Crecimiento Urbano UTDT-CIPUV 
Las transformaciones urbanas de las últimas décadas permiten hablar de una nueva geografía socio-residencial en el partido, que responde a una lógica de crecimiento y organización del espacio urbano en la que se contraponen los intereses específicos de los distintos actores involucrados y las estrategias que despliegan (FredianI, 2010). Dentro del partido conviven diversos procesos de ocupación que, a pesar de parecer contrapuestos, interactúan de manera dialéctica en relación con el mercado de suelo.

Por un lado, el crecimiento del parque habitacional dentro del casco fundacional se da a partir de la densificación de las construcciones y la lógica predominante del mercado inmobiliario. El casco urbano que durante el período 1980 y 2001 había decrecido en población recuperó un $5 \%$ de sus habitantes en el último período censal, en parte debido al proceso de densificación que desplegaron los desarrolladores inmobiliarios. Sin embargo, las tipologías predominantes de este desarrollo privado de parque habitacional se limitan al desarrollo de departamentos de uno o dos ambientes en torre, que reemplazan en muchos casos antiguas viviendas unifamiliares, lo cual disminuyó la oferta de viviendas para las familias numerosas en el centro (FrEAZA y Aón, 2014).

Por otro lado, en las áreas de la periferia, el crecimiento del parque habitacional se da de forma expansiva y diferenciada a partir de diversas lógicas. Estos incrementos poblacionales han ocupado en los últimos diez años 7053 nuevas hectáreas, con densidades de

Tabla III

\begin{tabular}{|c|c|c|c|c|c|c|c|c|c|c|}
\hline \multicolumn{11}{|c|}{ Población y Hogares Sector Crecimiento La Plata 2001-2010 } \\
\hline \multirow[t]{2}{*}{ Área } & \multicolumn{3}{|c|}{ Población } & \multicolumn{2}{|c|}{ Hogares 2010} & \multirow{2}{*}{$\begin{array}{c}\text { h1 } \\
\%\end{array}$} & \multirow{2}{*}{$\begin{array}{c}\text { h2 } \\
\%\end{array}$} & \multirow{2}{*}{$\begin{array}{c}\text { h3-4 } \\
\%\end{array}$} & \multirow{2}{*}{$\begin{array}{l}\text { h5 } \\
\%\end{array}$} & \multirow{2}{*}{$\begin{array}{r}\text { h6+ } \\
\% \\
\end{array}$} \\
\hline & 2001 & 2010 & \% Variación & Absolutos & $\%$ & & & & & \\
\hline NORTE & 5553 & 5849 & 5,3 & 1662 & 12,7 & 14,4 & 18,4 & 41,2 & 13,8 & 12,3 \\
\hline SUR & 5013 & 5926 & 18,2 & 1620 & 12,3 & 13,5 & 17,4 & 41,1 & 12,7 & 15,2 \\
\hline ESTE & 3609 & 5792 & 60,5 & 1748 & 13,3 & 16,6 & 21,6 & 40,5 & 11,6 & 9,7 \\
\hline OESTE & 23.637 & 28.723 & 21,5 & 8104 & 61,7 & 13,5 & 18,8 & 41,4 & 13,0 & 13,2 \\
\hline Totales & 37.812 & 46.290 & 22,4 & 13.134 & 100 & 14,0 & 19,0 & 41,2 & 12,9 & 12,9 \\
\hline
\end{tabular}

Fuente: elaboración propia con base en datos del Atlas de Crecimiento Urbano UTDT-CIPUV y Censos INDEC 2001-2010 
población promedio de 6.6 hab./ha (CIPUV, 2013). En estas nuevas áreas residenciales, viven alrededor de 46.290 personas en 13,134 hogares, de los cuales el $67 \%$ está conformado por tres o más personas, el $19 \%$ de los hogares por dos integrantes y el $14 \%$ está compuesto de hogares unifamiliares (tabla 3), configurando un patrón de ocupación de hogares con familias de gran tamaño en las diferentes periferias del partido (Aón, Giglo y ColA, 2017).

El desarrollo de dichos procesos se enmarca en las normativas que regulan qué y cómo se construye en la ciudad. Durante el período analizado (2003-2016) hubo un cambio en la normativa municipal. En la primera etapa estuvo efectiva la ordenanza 9231/00 de Ordenamiento Territorial y Uso Del Suelo en el Partido de La Plata, vigente desde año 2000 hasta 2009, mientras que en la segunda etapa se aprobó la ordenanza N. ${ }^{\circ} 10703 / 10$, que instaura el nuevo Código de Ordenamiento Urbano (COU), sancionada en abril de 2010 y vigente en la actualidad. Ambas normativas plantearon modelos similares: crecimiento concéntrico con mayores densidades de ocupación, concentración de actividades y equipamientos en el área fundacional y un desarrollo de periferias monofuncionales con zonas residenciales de baja densidad (FreaZA, Giglio y Aón, 2017).

\section{Planteo metodológico}

Para poder vincular el modelo de desarrollo expansivo residencial con las diferentes lógicas de ocupación en la periferia, se plantearon en este trabajo dos cortes temporales que abarcan el período 2003-2016. El primer período comienza en el año 2003 con el lanzamiento del Plan Federal de Vivienda; el segundo toma como punto de partida el lanzamiento de los planes de crédito para la construcción de vivienda propia ProCreAr en el año 2012. Ambos son representados cartográficamente tomando como base la mancha urbana del partido, determinada a partir de los datos e imágenes proporcionadas por el Atlas de Crecimiento Urbano (CIPUV, 2013).

El área de estudio delimitada para el análisis corresponde a la periferia del partido de La Plata, comprendida por dieciocho de las diecinueve delegaciones del partido, y dentro de la cual se reconocen cuatro grandes áreas, determinadas por los principales corredores de acceso: Periferia Norte, Periferia Sur, Periferia Oeste y Periferia Este (figura 2). Para el análisis de las lógicas de ocupación residencial se consideraron las siguientes variables: (1) el contexto socioeconómico, (2) las normativas de usos de suelo 
vigentes, (3) las políticas públicas de vivienda implementadas, (4) la localización de los nuevos barrios correspondientes a cada período (formales e informales) y (5) el grado de consolidación del área donde se insertaron dichos barrios.

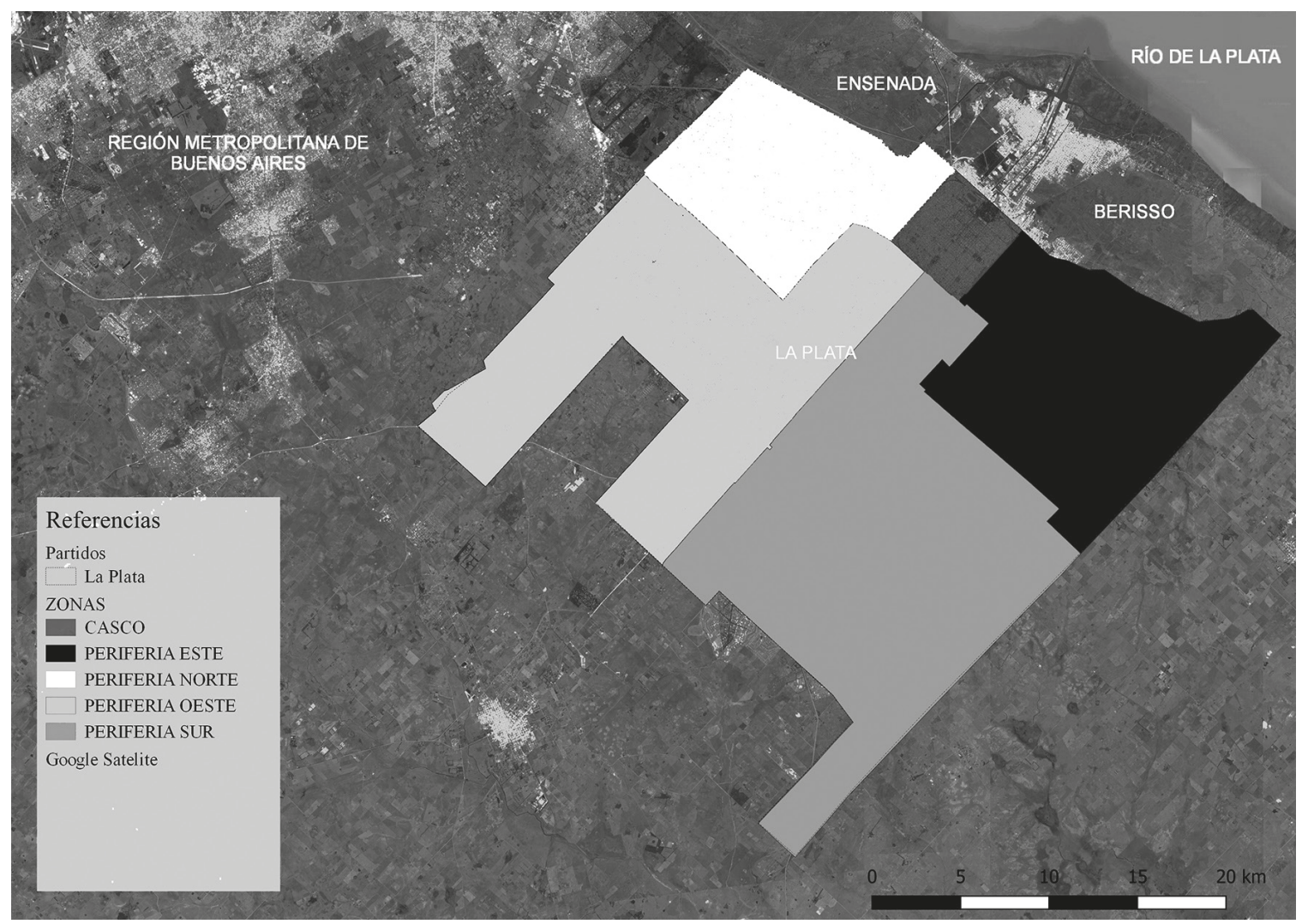

Figura 2. Delimitación de áreas de la periferia del partido de La Plata. Fuente: elaboración propia sobre la base de imágenes Google Earth y base cartográfica ARBA (2014) 
Tabla IV

Matriz de datos para el análisis del grado de consolidación urbana de las nuevas áreas residenciales por período

\begin{tabular}{|c|c|c|c|c|c|}
\hline $\begin{array}{l}\text { Variable } \\
\text { compleja }\end{array}$ & Dimensión & Variable & Indicador & & Valor \\
\hline \multirow{22}{*}{$\begin{array}{l}\text { Grado de } \\
\text { consoli- } \\
\text { dación } \\
\text { urbana }\end{array}$} & \multirow{4}{*}{ Ambiental } & $\begin{array}{l}\text { Riesgo de } \\
\text { inundación }\end{array}$ & $\begin{array}{l}\text { Ubicación sobre planicie } \\
\text { de inundación }\end{array}$ & $\begin{array}{l}0 \\
1\end{array}$ & $\begin{array}{l}\text { Ubicado fuera de planicie de inundación } \\
\text { Ubicados obre la planicie de inundación }\end{array}$ \\
\hline & & \multirow{3}{*}{ Canteras } & \multirow{3}{*}{ Cercanía a canteras } & 0 & A más de 300 metros \\
\hline & & & & 1 & A menos de 300 metros \\
\hline & & & & 2 & Cantera en el lote \\
\hline & \multirow{18}{*}{$\begin{array}{l}\text { Espacial- } \\
\text { Funcional }\end{array}$} & \multirow{6}{*}{$\begin{array}{l}\text { Acceso a la } \\
\text { movilidad }\end{array}$} & \multirow{3}{*}{$\begin{array}{l}\text { Distancia al centro } \\
\text { del casco urbano }\end{array}$} & 0 & Próximo-menos de 3 km \\
\hline & & & & 1 & Cercano-entre 3 y 6 km \\
\hline & & & & 2 & Lejano-más de 6 km \\
\hline & & & \multirow{3}{*}{$\begin{array}{l}\text { Cobertura de servicios } \\
\text { de transporte público }\end{array}$} & 0 & Bueno-menos de 300 m \\
\hline & & & & 1 & Regular-entre 300 y 600 m \\
\hline & & & & 2 & Malo-más de 600 m \\
\hline & & \multirow{12}{*}{$\begin{array}{l}\text { Cobertura } \\
\text { de servicios } \\
\text { de infra- } \\
\text { estructura }\end{array}$} & \multirow{3}{*}{$\begin{array}{l}\text { Cobertura de servicios } \\
\text { de agua potable }\end{array}$} & 0 & Buena $(80-100 \%)$ \\
\hline & & & & 1 & Regular (50-80 \%) \\
\hline & & & & 2 & Mala (menos del 50 \%) \\
\hline & & & \multirow{3}{*}{$\begin{array}{l}\text { Cobertura de } \\
\text { servicios de cloacas }\end{array}$} & 0 & Buena $(80-100 \%)$ \\
\hline & & & & 1 & Regular (50-80 \%) \\
\hline & & & & 2 & Mala (menos del 50 \%) \\
\hline & & & \multirow{3}{*}{$\begin{array}{l}\text { Cobertura de servicios } \\
\text { de gas natural }\end{array}$} & 0 & Buena (80-100 \%) \\
\hline & & & & 1 & Regular (50-80 \%) \\
\hline & & & & 2 & Mala (menos del 50 \%) \\
\hline & & & \multirow{3}{*}{$\begin{array}{l}\text { Cobertura de servicios } \\
\text { de electricidad }\end{array}$} & 0 & Buena $(80-100 \%)$ \\
\hline & & & & 1 & Regular (50-80 \%) \\
\hline & & & & 2 & Mala (menos del $50 \%$ ) \\
\hline
\end{tabular}


Tabla IV

Matriz de datos para el análisis del grado de consolidación urbana de las nuevas áreas residenciales por período

\begin{tabular}{|c|c|c|c|c|c|}
\hline $\begin{array}{l}\text { Variable } \\
\text { compleja }\end{array}$ & Dimensión & Variable & Indicador & & Valor \\
\hline \multirow{14}{*}{$\begin{array}{l}\text { Grado de } \\
\text { consoli- } \\
\text { dación } \\
\text { urbana }\end{array}$} & \multirow{9}{*}{$\begin{array}{l}\text { Económico } \\
\text { social }\end{array}$} & \multirow{9}{*}{$\begin{array}{l}\text { Acceso a } \\
\text { servicios } \\
\text { básicos }\end{array}$} & \multirow{3}{*}{$\begin{array}{l}\text { Acceso a centros } \\
\text { de salud }\end{array}$} & 0 & Bueno-menos de $600 \mathrm{~m}$ \\
\hline & & & & 1 & Regular-entre 600 y $1000 \mathrm{~m}$ \\
\hline & & & & 2 & Malo-más de $1000 \mathrm{~m}$ \\
\hline & & & \multirow{3}{*}{ Acceso a escuelas } & 0 & Bueno-menos de $600 \mathrm{~m}$ \\
\hline & & & & 1 & Regular-entre 600 y $1000 \mathrm{~m}$ \\
\hline & & & & 2 & Malo-más de $1000 \mathrm{~m}$ \\
\hline & & & \multirow{3}{*}{$\begin{array}{l}\text { Acceso a espacios } \\
\text { verdes públicos }\end{array}$} & 0 & Bueno-menos de $400 \mathrm{~m}$ \\
\hline & & & & 1 & Regular-entre 400 y $800 \mathrm{~m}$ \\
\hline & & & & 2 & Malo-más de $800 \mathrm{~m}$ \\
\hline & \multirow{5}{*}{$\begin{array}{l}\text { Legal- } \\
\text { Normativo }\end{array}$} & \multirow{3}{*}{$\begin{array}{l}\text { Localización } \\
\text { según } \\
\text { normativa }\end{array}$} & \multirow{3}{*}{ Ubicación según área } & 0 & En área urbana \\
\hline & & & & 1 & En área complementaria \\
\hline & & & & 2 & En área rural \\
\hline & & \multirow{2}{*}{$\begin{array}{l}\text { Uso según } \\
\text { zonificación }\end{array}$} & \multirow{2}{*}{$\begin{array}{l}\text { Uso según zona } \\
\text { normativa }\end{array}$} & 0 & Residencial \\
\hline & & & & 1 & No residencial \\
\hline
\end{tabular}

Fuente: elaboración propia sobre la base de matriz metodológica Cortizo (2018)

El análisis del contexto socioeconómico consiste en una breve descripción del momento que atravesaban el país y la ciudad de La Plata en cada uno de los períodos. Como parte de este contexto, se describen las normativas de usos de suelo vigentes y las políticas públicas de vivienda implementadas por el Estado. Para determinar la localización de los barrios, se desarrolló una cartografía base relevando los asentamientos informales a partir del Registro Provincial Público de Villas y Asentamientos Precarios (SSTUyV, 2015) y de los barrios desarrollados del Plan Federal y el crédito ProCreAr a partir de imágenes de Google Earth, notas periodísticas y registros de los proyectos urbanísticos (ANsEs, 2015). 
1. Fuentes de datos utilizadas para determinar el grado de consolidación urbana.

Dimensión ambiental: Informe Final Proyecto de Investigación Orientado PIO (UNLP, 2017). Dimensión espacial - funcional: Tesis doctoral "El tiempo de viaje como variable crítica para la planificación del transporte público masivo y el desarrollo urbano. Prospectivas para el Gran La Plata" (CoLA, 2019) y Datos censales (INDEC,2010).

Dimensión económicosocial: Registro Federal de Establecimientos de Salud Públicos y Privados (SIISA, 2018), Cartografía escolar (LÓPEZ, 2016), Relevamiento de espacios verdes de uso

público (JENSEN Y BIRCHE, 2017).

Dimensión legal-normativa: Zonificación del Código de Ordenamiento Urbano del Partido de La Plata (2010), actualizado en 2010 por tratarse de la normativa aplicada en los dos períodos para analizar.
Para el análisis del grado de consolidación del área donde se insertaron los nuevos barrios residenciales, se utilizó como base la metodología desarrollada por CoRTizo en su tesis de maestría (2018). La información obtenida fue ordenada en una matriz de datos, donde se determinaron cuatro dimensiones principales: 1) ambiental; 2) espacial-funcional; 3) económico-social y 4) legal-normativa (tabla 4). El reconocimiento de dichas dimensiones permite dar cuenta de las características del área donde se insertaron los barrios y el grado de acceso a la ciudad y sus servicios. De este modo, a cada unidad de análisis (barrio) se le asignaron valores - entre 0 y 24- según el grado de consolidación del área: alto $=0$ a 8 , medio $=9$ a 16 y bajo $=17$ a 24 . A continuación, se detallan las dimensiones de análisis ${ }^{1}$ :

\section{Lógicas de ocupación residencial en la periferia del partido de La Plata}

\section{Primer período 2003-2012}

Luego de la crisis de 2001-2002, Argentina experimentó un fuerte crecimiento económico, siendo la industria de la construcción y el sector inmobiliario dos de las actividades que impulsaron fuertemente este proceso (Del Río y RelLi, 2013). En el contexto del "boom inmobiliario" que se dio a nivel nacional, La Plata no fue una excepción. Según datos sistematizados por BAER (2011), el municipio de La Plata fue el distrito provincial que más superficie permisada para construir otorgó entre 2003 y 2008 en toda la Región Metropolitana de Buenos Aires. Sin embargo, como aclaran Del Río y Relli (2013), la expansión de la oferta inmobiliaria no se tradujo en mejores condiciones de acceso al espacio urbano.

A la par del crecimiento en la oferta de inmuebles se produjo un incremento de la informalidad urbana y de la tasa de inquilinos. En el último período intercensal (INDEC, 2001, 2010), hubo un incremento del 3,1 \% al 4,1 \% de la informalidad urbana y del 14,8 \% al 20,5 $\%$ de hogares inquilinos, lo que marca una inflexión en la estructura de tenencia y permite observar un creciente proceso de inquilinización. Dicho aspecto, advierte Del Río, se explica por "la creciente disociación de la demanda solvente asociada a la inversión especulativa de la demanda final de la vivienda" (Del Río, Langard y Relli, 2014, p. 2). Durante este primer período, es posible observar cómo la mancha urbana se extiende sobre la periferia del partido a partir de las redes viarias con acceso al casco fundacional (figura 3). 


\section{Lógicas de ocupación y acceso al suelo en procesos de desarrollo residencial expansivo.}

El caso de la periferia del partido de La Plata (2003-2016)

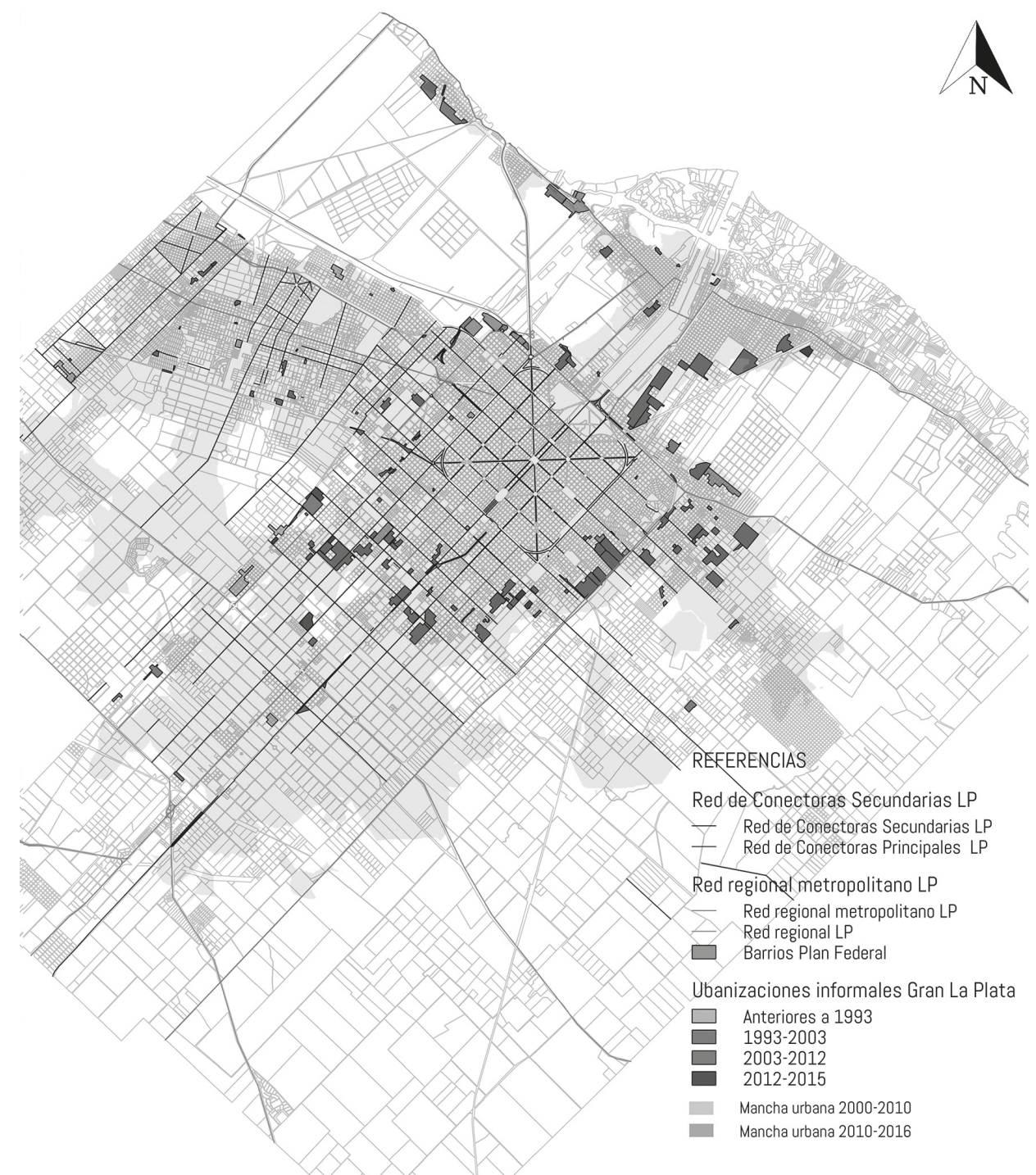

Figura 3. Asentamientos y planes federales. Período 2003-2012, Gran La Plata. Fuente: elaboración propia sobre la base de datos del Atlas de Crecimiento Urbano (CIPUV, 2013), imágenes Google Earth y Registro Provincial de Villas y Asentamientos (SSTUyV, 2015) 
Figura 4. Urbanizaciones informales Gran La Plata, redes de conexión y delegaciones principales 2018. Fuente: elaboración propia sobre la base de imágenes Google Earth, Registro Provincial de

Villas y Asentamientos SSTUyV 2015

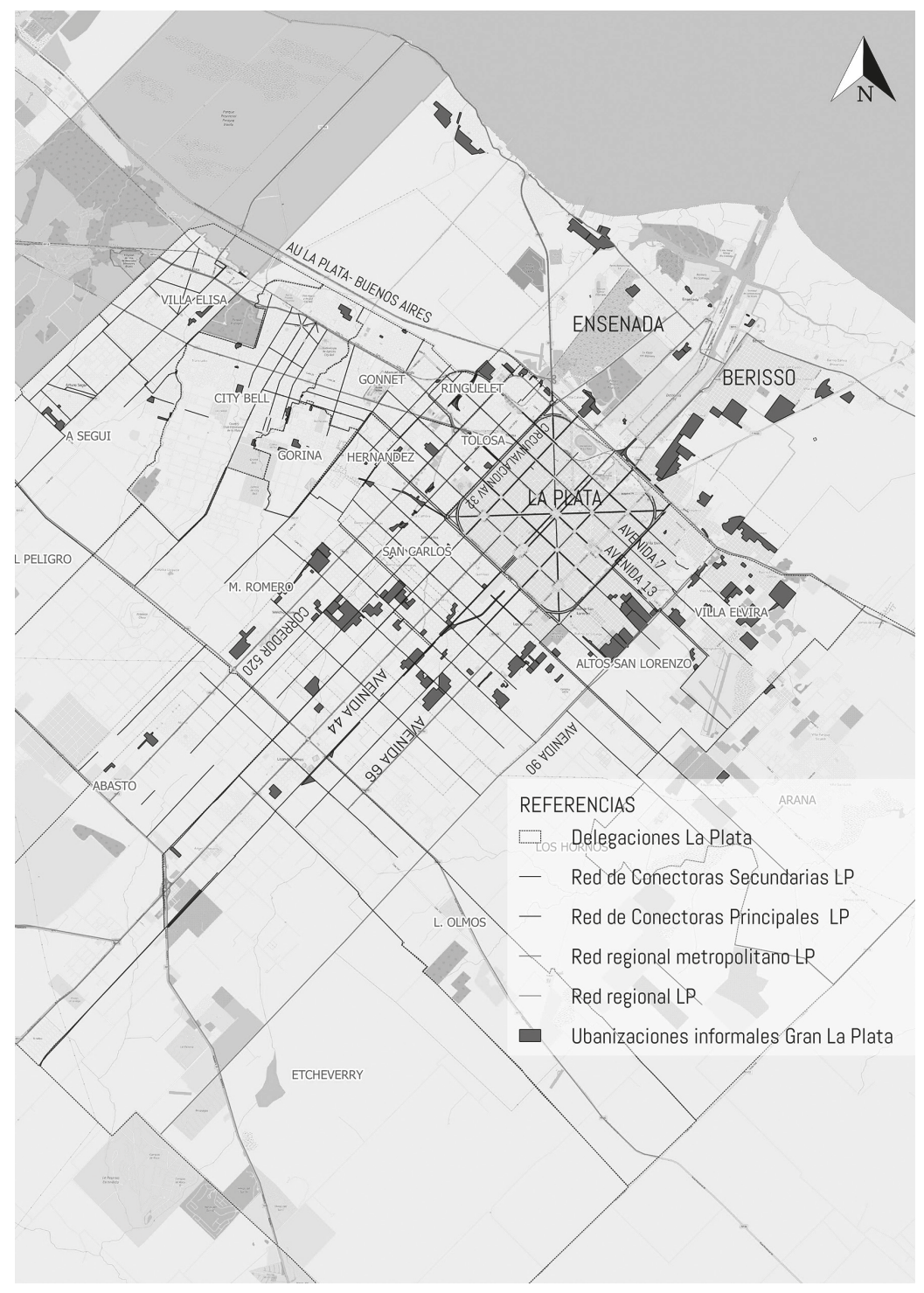


Entre los años 2003 y 2012 surgieron en la periferia del partido de La Plata un total de 86 urbanizaciones informales que duplicaron la cantidad de asentamientos preexistentes, en parte como consecuencia de la crisis sufrida en el año 2001. Dichos asentamientos se localizaron en los bordes de la mancha urbana, principalmente en la periferia Este, en las delegaciones de Altos de San Lorenzo y villa Elvira. También se concentraron en los bordes de la periferia Oeste y Sur con el casco urbano, en las delegaciones de San Carlos y Los Hornos, donde ya existían otros asentamientos. El resto se localizó mayoritariamente en el borde de la periferia Este, en el camino que conduce al centro de Berisso, y conformó lo que hoy se conoce como villa Argüello (figura 4). Esta lógica de ocupación en torno de las vías de acceso es muy común en los asentamientos, ya que al no poder garantizar un lugar dentro de la centralidad buscan un punto desde donde puedan acceder de manera rápida a esta, a través del sistema de transporte público o medios de tracción a sangre (animal o humana).

El grado de consolidación urbana de las áreas donde se localizaron las urbanizaciones informales fue de un grado medio en el $66 \%$ de los casos, un $20 \%$ de los asentamientos se localizaron en áreas de baja consolidación urbana y apenas el 14 \% de los barrios se asentaron en áreas de una alta consolidación urbana (figura 5). Con respecto a la dimensión ambiental, se puede afirmar que los lotes que ocupan los asentamientos informales presentan, por lo general, algunas características ambientales deficientes (tabla 5), ya sea por ser terrenos anegables (75 \% de los casos), porque carecen de servicios de infraestructura como el asfalto, lo cual dificulta el acceso a los barrios en días de lluvia, o por ser áreas con residuos o próximas a sectores de cavas o canteras (34 \% de los casos se localizan a 300 metros o menos de una cantera). En cuanto a la dimensión espacial-funcional, el $51 \%$ de los asentamientos se localizó en las cercanías del casco, entre 3 y $6 \mathrm{~km}$ del centro, y el restante 49 \% tuvo que localizarse a más de $6 \mathrm{~km}$ del centro geográfico de la ciudad (tabla 5). En relación con el acceso a la movilidad, el 66 \% de los asentamientos tiene un acceso regular a la red de transporte público, particularmente los que se ubican en la periferia Este, solo el 17 $\%$ tiene una parada de micros a menos de $300 \mathrm{~m}$ del barrio y el restante $17 \%$ no entra en el área de cobertura (tabla 5). Con respecto a la cobertura de servicios de infraestructura, los asentamientos tienen una buena cobertura de agua y electricidad, con $71 \%$ y $97 \%$ de los barrios con buena cobertura, respectivamente. Sin embargo, la cobertura de la red cloacal y de gas es baja a nula en casi el $90 \%$ de los casos (tabla 5).

Pasando al análisis de la dimensión económico-social, se puede observar una tendencia crítica en el acceso a los centros de salud, con un 80 \% de los asentamientos localizados a más 
de 1000 m de un centro de salud. Con respecto al acceso a la educación, se constató que el 76 $\%$ de los asentamientos tenía un acceso regular a establecimientos educativos y solo el $11 \%$ contaba con una escuela a menos de $600 \mathrm{~m}$ de su barrio. En lo referente al acceso a espacios verdes públicos, el $48 \%$ de los asentamientos está a más de $1000 \mathrm{~m}$ de un espacio verde, pero un 29 \% tiene acceso a espacio verde a menos de $400 \mathrm{~m}$ de sus barrios; sin embargo, varios de estos espacios surgieron de forma espontánea por el propio interés de los vecinos (tabla 5). Por último, analizando la dimensión legal normativa se puede observar que el 63 \% de los asentamientos se localizó en áreas "urbanas” de uso "residencial” (tabla 5), ya que —como se mencionó anteriormente - la lógica de ocupación de los asentamientos busca instalarlos en zonas lo más próximas posible a las centralidades, en torno de los principales corredores, ocupando los intersticios y vacíos que va dejando la trama urbana.

Por otro lado, se corresponde con este período el desarrollo del Programa Federal de Vivienda, una política de acceso a la vivienda que tiene sus inicios en el año 2003. Aramburu y Chiara (2016) señalan cómo la reincorporación de la cuestión habitacional a la agenda pública durante la presidencia de Néstor Kirchner provocó un rotundo giro en materia de políticas habitacionales, ya que persiguió tres objetivos: la generación de empleo, la disminución del déficit habitacional y la reactivación de la economía local a partir de la movilización del mercado de la construcción. Estos objetivos fueron puestos en práctica por medio de los diversos programas, conocidos como los Planes Federales de Vivienda.

Las diferentes etapas de los planes se ocuparon de cubrir diversas necesidades; por un lado, la construcción de viviendas nuevas y, por otro lado, la ampliación o refacción de viviendas deficitarias. En los primeros programas la construcción se organizaba a partir de cooperativas de trabajo conformadas por los beneficiaros del Programa Jefas y Jefes de Hogar. De este modo, incluía organizaciones sociales en su ejecución y articulaba diferentes instancias gubernamentales, como el Ministerio de Planificación Federal, Inversión Pública y Servicios de la Nación, la Subsecretaría de Desarrollo Urbano y Vivienda, el Ministerio de Desarrollo Social y el Instituto Nacional de Economía Social y Solidaria (Aramburu y Chiara, 2016). También fueron partícipes en la ejecución de los programas actores del sector privado. Por un lado, se encuentra el sector vinculado con la industria de la construcción, es decir, las empresas constructoras y aquellas relacionadas con los rubros que producen insumos para la construcción. Por otro lado, están los propietarios de tierra urbana o de tierra urbanizable, cuyos predios, ante el lanzamiento del programa, se vieron en creciente demanda, lo que posibilitó el surgimiento de una lógica 
eminentemente especulativa. En este sentido, Aramburu y Chiara destacan la ausencia de una política clara en los convenios marco acerca de las tierras para utilizar para la construcción de viviendas, por lo cual se generó un claro conflicto en el acceso al soporte que permitiera la ejecución de dichas viviendas.

En el partido de La Plata se reconocen tres unidades de análisis o barrios que corresponden a dicho plan de viviendas, algunos de los cuales no llegaron a completarse y dejaron muros y esqueletos portantes a mitad de construcción. Dichos barrios se concentran en el sector norte, en el límite del casco urbano y la delegación de Tolosa. El más reconocido es el barrio de "El Mercadito", el complejo detrás del Mercado Central en Ringuelet en el límite con Ensenada. Junto a "La bajada" y "El mercadito 2", los tres barrios conforman un conjunto de 870 viviendas construido en el año 2005 (figura 3). En él habitan hoy unas 3700 personas, aproximadamente (INDEC, 2010).

A pesar de la proximidad al casco urbano, el grado de consolidación urbana de estos barrios es de un nivel medio (figura 5). En relación con la dimensión ambiental, la situación de los tres barrios resulta crítica, ya que los tres están asentados en áreas anegables y se ubican a menos de $300 \mathrm{~m}$ de una cantera, hecho que propicia situaciones de riesgo hídrico y salubridad para su población (tabla 5). En cuanto a la dimensión espacial-funcional, el conjunto dista unos $4.9 \mathrm{~km}$ del área central de la ciudad, mientras que su centralidad cotidiana más próxima es el centro de Tolosa, algo más cercana $(2.7 \mathrm{~km})$, pero difícilmente accesible por la trama circulatoria en que está implantado el primero. En lo que respecta al acceso a la movilidad, la zona carece de servicios de transporte público que ingresen en el barrio; sin embargo, tienen acceso a algunas líneas de transporte que transitan por circunvalación a 500 metros en el caso del barrio "La Bajada" (tabla 5). En relación con la cobertura de servicios de infraestructura, los barrios tienen una buena cobertura de agua y electricidad, pero no así de cloacas y gas de red, con una cobertura baja a nula (tabla 5).

Analizando la dimensión económico-social, se puede observar que en lo referente al acceso a los servicios básicos los tres barrios tienen una baja accesibilidad tanto a centros de salud y establecimientos educativos como a espacios verdes de uso público, con la excepción de “La Bajada”, por su proximidad a la circunvalación de la avenida 32 del casco urbano (tabla 5). Por último, en relación con la dimensión legal normativa, a pesar de que dos de los tres barrios se encuentran en un área definida como "urbana”, ninguno de los tres se localiza en un terreno destinado a uso "residencial” acorde con la zonificación (tabla 5). 
Figura 5. Grado de consolidación urbana de los barrios conformados en el período 2003-2012.

Fuente: elaboración propia sobre la base de base cartográfica parcelaria ARBA (2014), Registro Provincial de Villas y Asentamientos (SSTUyV, 2015) e

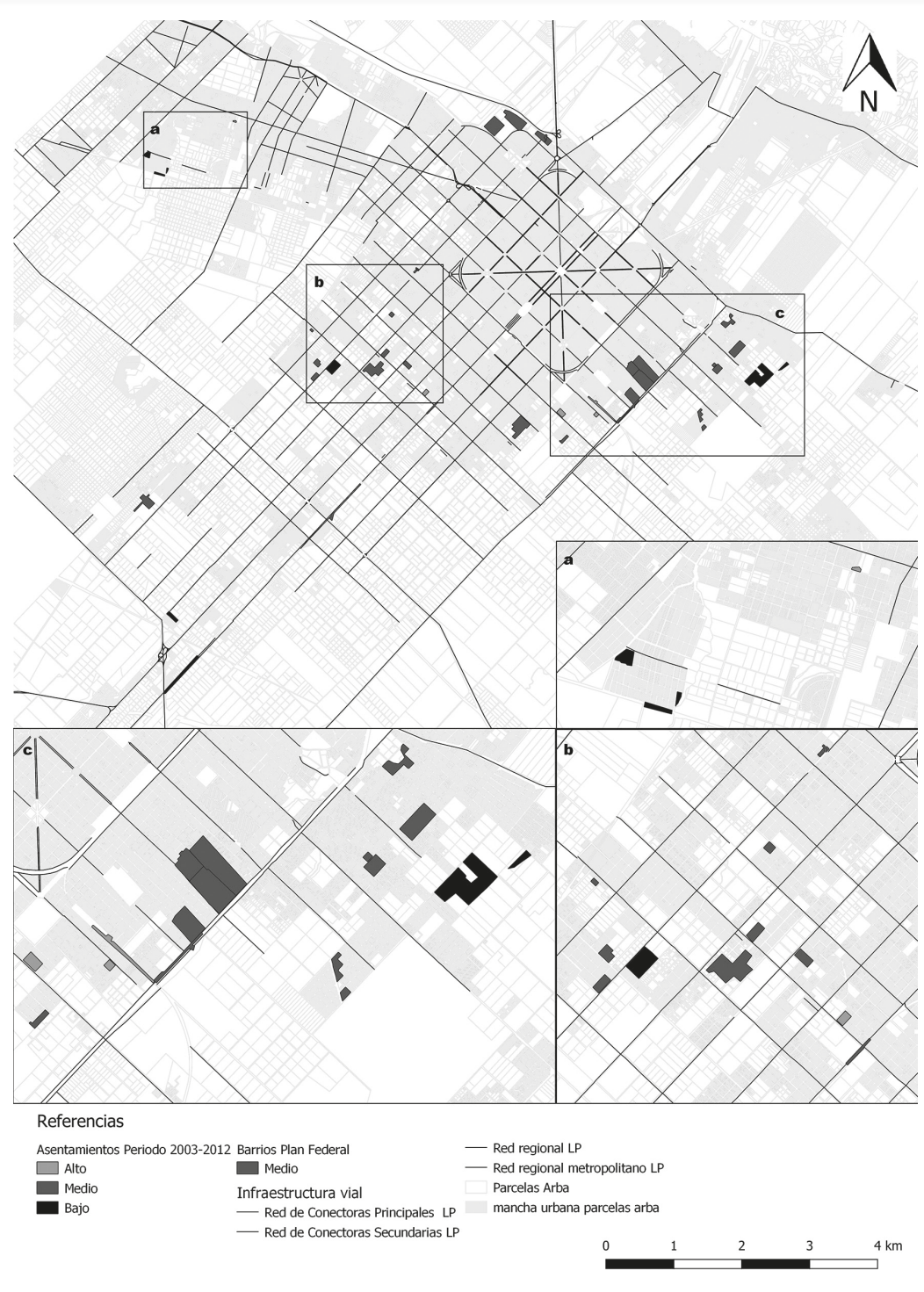
imágenes Google Earth 


\section{Segundo período 2012-2016}

Entre los años 2012 y 2016 es posible observar cómo el crecimiento de la mancha urbana de La Plata aumentó drásticamente, especialmente en el sector noroeste del partido. En esos cuatro años se originaron trece nuevas urbanizaciones de tipo informal, mayoritariamente en las localidades de San Carlos, Melchor Romero, Abasto, Olmos y en el partido de Berisso (figura 6). Puede afirmarse que, si bien no existen áreas del partido libres de asentamientos informales, es posible distinguir algunas preferencias de localización en el interior del eje sudeste y algunos sectores de la zona sudoeste del partido. Como ya se mencionó, los asentamientos se localizan generalmente en terrenos de alto riesgo ambiental, no aptos para el uso residencial y con dificultades en el acceso a las redes de servicios básicos, y su lógica de necesidad está en relación con las vías y los accesos que permiten una mayor cercanía a los diferentes modos de transporte.

El grado de consolidación urbana de las áreas donde se localizaron las urbanizaciones informales en este período fue medio en el $91 \%$ de los casos (figura 7). Al analizar la dimensión ambiental se confirma - así como en los asentamientos del período anterior-que los lotes que ocupan los asentamientos informales son terrenos anegables en el $73 \%$ de los casos, pero la mayoría de los barrios se encuentran alejados de las áreas de explotación de canteras o cavas; solo el 18 \% se encuentra en las proximidades de estas (tabla 5). Con respecto a la dimensión espacial-funcional, el $73 \%$ de los asentamientos se localizó a más de $6 \mathrm{~km}$ del centro geográfico de la ciudad, y solo el $27 \%$ se encuentra próximo (tabla 5). En relación con la cobertura del transporte público, solo el $18 \%$ de los asentamientos tiene una parada de transporte a menos de $300 \mathrm{~m}$, el $45 \%$ debe caminar entre 300 y 600 metros y el 37 \% no entra en el área de cobertura de la red (tabla 5). En lo que respecta a la cobertura de servicios de infraestructura, los asentamientos tienen una buena cobertura de agua y electricidad, entre el 80 y el $90 \%$, pero, al igual que en los casos anteriores, la cobertura de la red cloacal y de gas es mala en el $90 \%$ de los casos (tabla 5).

Acerca de la dimensión económico-social pueden observarse tendencias similares a las percibidas en los asentamientos del período 2003-2012: una mala accesibilidad a centros de salud ( $83 \%$ de los asentamientos no cuenta con un centro de atención a menos de 1000 m), 
Figura 6. Asentamientos y planes ProCreAr, período 2012-2016. Gran La Plata. Fuente: elaboración propia sobre la base de imágenes Google Earth, Registro Provincial de Villas y Asentamientos (SSTUyV, 2015) y registros proyectos urbanísticos ProCreAr (ANSES, 2015)

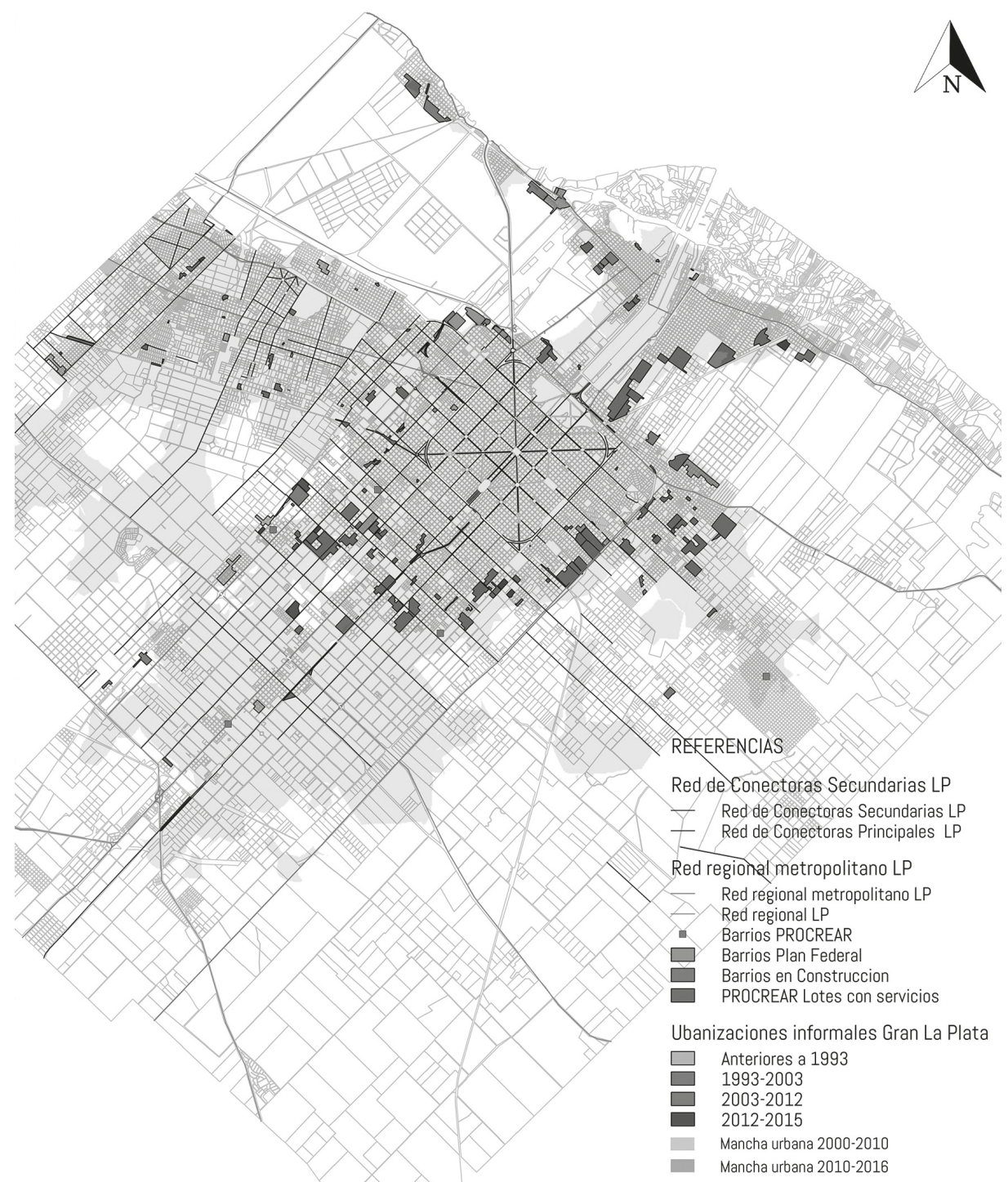

Cuaderno Urbano. Espacio, Cultura, Sociedad - Vol. 27 - N. ${ }^{\circ} 27$ (Diciembre de 2019)- Pp. 053-086 - ISSN1666-6186 
un regular acceso a establecimientos educativos (el $73 \%$ de los casos tiene una escuela a partir de los $600 \mathrm{~m}$ ) y una proximidad variable a espacios verdes, un $36 \%$ tiene una plaza a menos de 400 m; otro $36 \%$, entre 400 y 800 m y un $28 \%$, a más de 800 m (tabla 5). En cuanto a la dimensión legal normativa, se puede observar que el $55 \%$ de los asentamientos se instaló en áreas “urbanas”, el 36 \% en áreas “complementarias” y el 9 \% en áreas denominadas como "rurales”, mientras que un 73 \% de dichos barrios se asentó en un terreno destinado por la zonificación para usos "no residenciales” (tabla 5), lo que indica la clandestinidad de dichas ocupaciones.

El surgimiento Programa de Crédito Argentino (ProCreAr) implicó la apertura de un segmento de oferta no cubierto por el mercado hipotecario, el cual se encontraba contraído y destinado exclusivamente a sectores de altos ingresos. Del Río (2016) distingue dos momentos en la cronología del programa. En un primer momento los recursos se orientaron al desarrollo de (1) proyectos urbanísticos, (2) créditos para la construcción, (3) ampliación/terminación y (4) refacción de la vivienda. Un segundo momento puede reconocerse a partir de septiembre de 2013, cuando, dadas las dificultades que los beneficiarios manifestaron en el acceso al suelo urbano, se agregaron dos nuevas líneas de crédito: compra de terreno y adquisición de vivienda para estrenar. Estas dos últimas líneas pretendían aliviar el problema del acceso al suelo. Sin embargo, como señala Del Río (2016), la línea de compra de terreno, lejos de contribuir a la resolución de la problemática del acceso al suelo, retroalimentó el fuerte proceso especulativo por parte de los propietarios de la tierra.

En dicho contexto se pudo observar cómo a partir del año 2012 el crecimiento de la mancha urbana aumentó drásticamente, en parte gracias al desarrollo de los barrios impulsados por el ProCreAr (figura 6). Un caso distintivo es el de Parque Sicardi, un barrio tradicional de segundas residencias y casas quinta localizado a $17 \mathrm{~km}$ del centro, el cual presenta un déficit de infraestructura en su conectividad vial y en el servicio de transporte público, lo que produce una alta dependencia del automóvil particular para sus residentes (Aón, Giglio y ColA, 2017).

Como consecuencia de este proceso, solamente en el año 2015 se aprobó la construcción en 2100 lotes ProCreAr ${ }^{2}$, de los cuales 546 se localizaron en la periferia Norte (26 \%) en Arturo Seguí, Gorina y villa Elisa, unos 324 lotes (16 \%) en la periferia Este de villa Elvira, Arana y Altos de San Lorenzo y, por último, unos 1230 lotes en las periferias Sur y Oeste del partido en las delegaciones de San Carlos, Melchor Romero, Abasto, Olmos y Etcheverry (figura 6).
2. Dato extraído de nota en el Diario El Día 1/6/2015. http:// www.eldia.com/la-provincia/ por-el-plan-procrear-laciudad-aumentara-esteano-su-superficie-en-120manzanas-60287. 
Figura 7. Grado de consolidación urbana de los barrios conformados en el período 2003-2012. Fuente: elaboración propia según datos de la base cartográfica parcelaria ARBA (2014) Registro Provincial de Villas y Asentamientos (SSTUyV, 2015) y registro de proyectos urbanísticos ProCreAr (ANsEs, 2015)

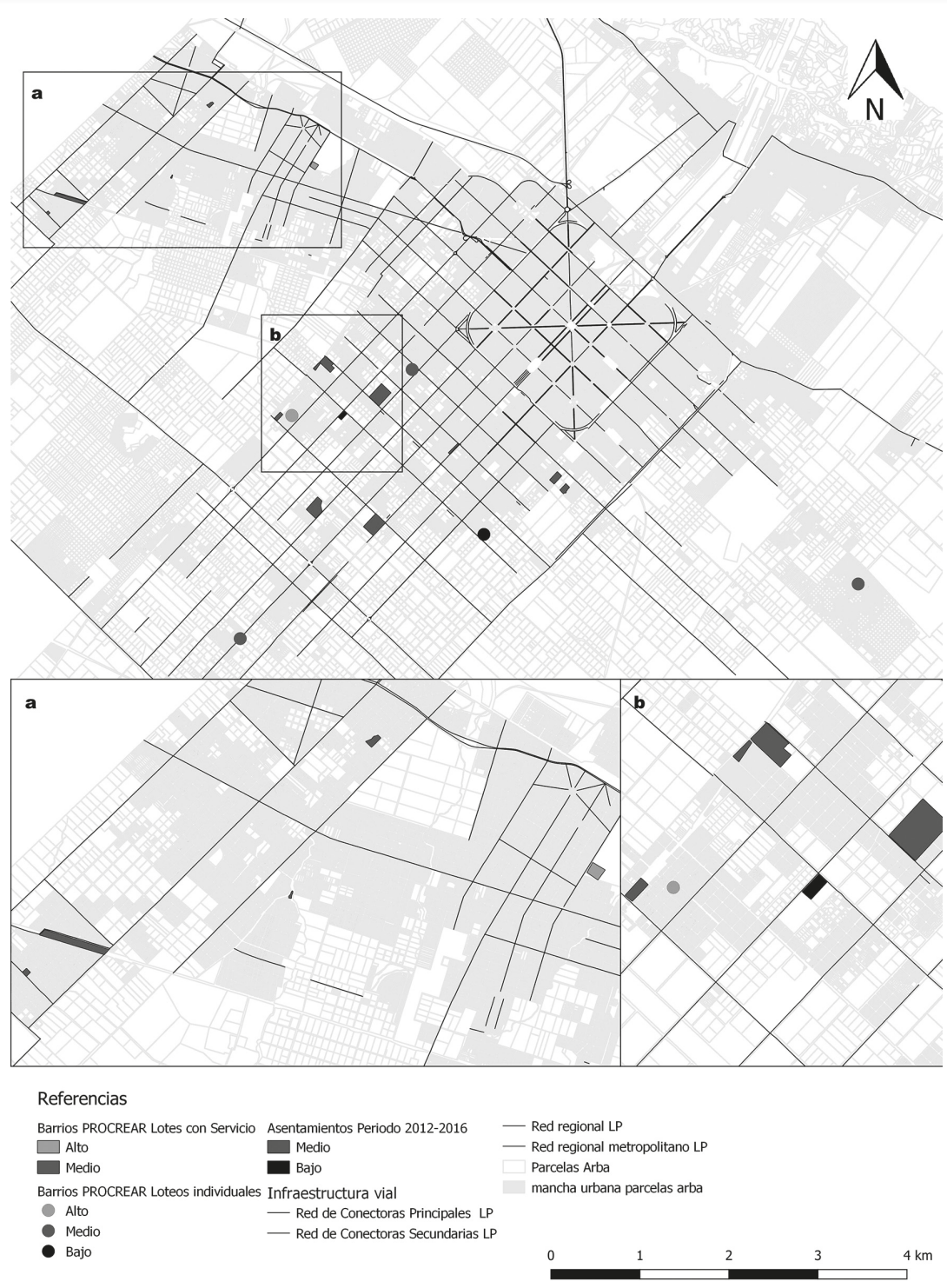

Cuaderno Urbano. Espacio, Cultura, Sociedad - Vol. 27 - N. ${ }^{\circ} 27$ (Diciembre de 2019)- Pp. 053-086 - ISSN1666-6186 
Para analizar el grado de consolidación de los barrios producto de la implementación del crédito ProCreAr se distinguen, por un lado, aquellos que surgieron a partir del sub-programa "lotes con servicios" implementado por el Estado nacional a nivel local y, por otro lado, los barrios que surgieron de la venta y subdivisión de lotes privados adquiridos por los beneficiarios del crédito. Se considera que las lógicas y dinámicas de inserción de dichos barrios varían debido a los roles de los actores involucrados de manera directa en su ejecución (propietarios de lotes privados, beneficiarios del programa, municipio, entre otros).

Los barrios del programa "lotes con servicio" tienen un grado de consolidación medio en el $75 \%$ de los casos y alto en el $25 \%$ de los casos. Los barrios de loteos individuales tienen un grado de consolidación medio en el $60 \%$ de los casos, un $20 \%$ tiene un grado de consolidación alto y otro 20 \% un grado de consolidación bajo (figura 7). En cuanto a la dimensión ambiental, la situación es diferente según el programa: los "lotes con servicio" presentan un $75 \%$ de casos en terrenos no anegables y el $100 \%$ por fuera de las cercanías de cavas o canteras. Los lotes individuales, en cambio, presentan un $60 \%$ de casos en terrenos no anegables, pero el $60 \%$ de los terrenos se encuentran próximos a una cava o cantera (tabla 5). En cuanto a la dimensión espacial-funcional, ambos programas comparten la misma dificultad: la mayoría de los barrios se localiza a más de $6 \mathrm{~km}$ del centro geográfico de la ciudad ( $80 \%$ en el caso de los loteos individuales y $100 \%$ en los proyectos de lotes con servicio. Ver tabla 5).

Con relación al acceso a la movilidad, los barrios conformados por loteos individuales tienen buen acceso a la red de transporte ( $80 \%$ de los casos); en cambio, en los barrios de lotes por servicio solo el 50 \% tiene un buen acceso al transporte (tabla 5). En relación con la cobertura de servicios de infraestructura, los barrios de lotes con servicio tienen una óptima cobertura de red de agua potable (un $75 \%$ ), mientras que en los barrios de lotes individuales solo alcanza al $40 \%$ de los casos. Todos los barrios tienen cobertura de red eléctrica y presentan un severo déficit en la cobertura de red gas (de $75 \%$ a $80 \%$ según el programa) y del servicio de cloacas: el $100 \%$ de los casos tiene una cobertura regular o mala del servicio (tabla 5).

Analizando la dimensión económico-social se puede observar una tendencia negativa pronunciada en el acceso a los centros de salud para los barrios de ambos programas: el $80 \%$ de los barrios de lotes individuales no tiene un buen acceso a centros de salud, y en el caso del 
Tabla V

Matriz de análisis del grado de consolidación urbana de las áreas según el tipo de barrio y período

\begin{tabular}{|c|c|c|c|c|c|c|c|}
\hline \multirow{3}{*}{ 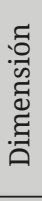 } & \multirow{3}{*}{ Indicadores } & \multirow{3}{*}{ Valores } & \multicolumn{5}{|c|}{ Unidad de análisis } \\
\hline & & & \multicolumn{2}{|c|}{ Periodo 2003-2012 } & \multicolumn{3}{|c|}{ Periodo 2012-2016 } \\
\hline & & & $\begin{array}{c}\text { Barrios } \\
\text { Plan Federal }\end{array}$ & $\begin{array}{c}\text { Asenta- } \\
\text { mientos } \\
\text { 2003-2012 }\end{array}$ & $\begin{array}{c}\text { ProCreAr } \\
\text { Lotes } \\
\text { individuales }\end{array}$ & $\begin{array}{l}\text { ProCreAr } \\
\text { Lotes con } \\
\text { servicios }\end{array}$ & $\begin{array}{c}\text { Asenta- } \\
\text { mientos } \\
\text { 2012-2016 }\end{array}$ \\
\hline \multirow{5}{*}{ 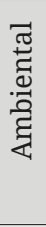 } & \multirow{2}{*}{$\begin{array}{l}\text { Riesgo de } \\
\text { inundación }\end{array}$} & No anegable & $0 \%$ & $25 \%$ & $60 \%$ & $75 \%$ & $27 \%$ \\
\hline & & Anegable & $100 \%$ & $75 \%$ & $40 \%$ & $25 \%$ & $73 \%$ \\
\hline & \multirow{3}{*}{$\begin{array}{l}\text { Cercanía a } \\
\text { Canteras }\end{array}$} & $\mathrm{A}+$ de 300 metros & $0 \%$ & $66 \%$ & $40 \%$ & $100 \%$ & $82 \%$ \\
\hline & & A - de 300 metros & $100 \%$ & $23 \%$ & $60 \%$ & 0 & $18 \%$ \\
\hline & & Cantera en el lote & $0 \%$ & $11 \%$ & 0 & 0 & $0 \%$ \\
\hline \multirow{15}{*}{ 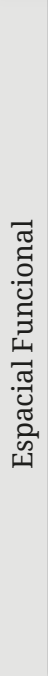 } & \multirow{3}{*}{$\begin{array}{l}\text { Distancia } \\
\text { centro }\end{array}$} & Próximo-menos de 3 km & $0 \%$ & $0 \%$ & 0 & 0 & $0 \%$ \\
\hline & & Cercano-entre 3 y 6 km & $100 \%$ & $51 \%$ & $20 \%$ & 0 & $27 \%$ \\
\hline & & Lejano-más de 6 km & $0 \%$ & $49 \%$ & $80 \%$ & $100 \%$ & $73 \%$ \\
\hline & \multirow{3}{*}{ Acceso TP } & Bueno-menos de $300 \mathrm{~m}$ & $33 \%$ & $17 \%$ & $80 \%$ & $50 \%$ & $18 \%$ \\
\hline & & Regular-entre 300 y 600 m & $66 \%$ & $66 \%$ & 0 & $50 \%$ & $45 \%$ \\
\hline & & Malo- más de 600 m & $0 \%$ & $17 \%$ & $20 \%$ & 0 & $37 \%$ \\
\hline & \multirow{3}{*}{ Agua } & Buena $(80-100 \%)$ & $100 \%$ & $71 \%$ & $40 \%$ & $75 \%$ & $82 \%$ \\
\hline & & Regular (50-80\%) & $0 \%$ & $3 \%$ & $20 \%$ & $25 \%$ & $0 \%$ \\
\hline & & Mala (menos del 50\%) & $0 \%$ & $26 \%$ & $40 \%$ & 0 & $18 \%$ \\
\hline & \multirow{3}{*}{ Cloacas } & Buena $(80-100 \%)$ & $0 \%$ & 0 & 0 & 0 & $0 \%$ \\
\hline & & Regular (50-80\%) & $33 \%$ & $11 \%$ & $20 \%$ & $25 \%$ & $10 \%$ \\
\hline & & Mala (menos del 50\%) & $66 \%$ & $89 \%$ & $80 \%$ & $75 \%$ & $90 \%$ \\
\hline & \multirow{3}{*}{ Gas } & Buena $(80-100 \%)$ & $0 \%$ & 0 & $20 \%$ & $25 \%$ & $0 \%$ \\
\hline & & Regular (50-80\%) & $0 \%$ & $14 \%$ & 0 & 0 & $10 \%$ \\
\hline & & Mala (menos del 50\%) & $100 \%$ & $86 \%$ & $80 \%$ & $75 \%$ & $90 \%$ \\
\hline
\end{tabular}


Matriz de análisis del grado de consolidación urbana de las áreas según el tipo de barrio y período

\begin{tabular}{|c|c|c|c|c|c|c|c|}
\hline \multirow{3}{*}{ 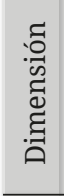 } & \multirow{3}{*}{ Indicadores } & \multirow{3}{*}{ Valores } & \multicolumn{5}{|c|}{ Unidad de análisis } \\
\hline & & & \multicolumn{2}{|c|}{ Periodo 2003-2012 } & \multicolumn{3}{|c|}{ Periodo 2012-2016 } \\
\hline & & & $\begin{array}{c}\text { Barrios } \\
\text { Plan Federal }\end{array}$ & $\begin{array}{c}\text { Asenta- } \\
\text { mientos } \\
\text { 2003-2012 }\end{array}$ & $\begin{array}{c}\text { ProCreAr } \\
\text { Lotes } \\
\text { individuales }\end{array}$ & $\begin{array}{l}\text { ProCreAr } \\
\text { Lotes con } \\
\text { servicios }\end{array}$ & $\begin{array}{c}\text { Asenta- } \\
\text { mientos } \\
2012-2016\end{array}$ \\
\hline \multirow{3}{*}{ 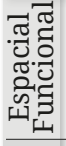 } & \multirow{3}{*}{ Electricidad } & Buena (80-100\%) & $100 \%$ & $97 \%$ & $100 \%$ & $100 \%$ & $91 \%$ \\
\hline & & Regular (50-80\%) & $0 \%$ & $3 \%$ & 0 & 0 & $9 \%$ \\
\hline & & Mala (menos del 50\%) & $0 \%$ & 0 & 0 & 0 & $0 \%$ \\
\hline \multirow{9}{*}{ 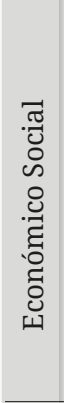 } & \multirow{3}{*}{ Salud } & Bueno-menos de $600 \mathrm{~m}$ & $0 \%$ & $3 \%$ & 0 & 0 & $0 \%$ \\
\hline & & Regular-entre 600 y $1000 \mathrm{~m}$ & $0 \%$ & $17 \%$ & $20 \%$ & $25 \%$ & $18 \%$ \\
\hline & & Malo- más de 1000 m & $100 \%$ & $80 \%$ & $80 \%$ & $75 \%$ & $82 \%$ \\
\hline & \multirow{3}{*}{ Educación } & Bueno-menos de $600 \mathrm{~m}$ & $0 \%$ & $11 \%$ & $20 \%$ & $25 \%$ & $18 \%$ \\
\hline & & Regular-entre 600 y 1000 m & $0 \%$ & $74 \%$ & $20 \%$ & $75 \%$ & $73 \%$ \\
\hline & & Malo- más de 1000 m & $100 \%$ & $15 \%$ & $60 \%$ & 0 & $9 \%$ \\
\hline & \multirow{3}{*}{$\begin{array}{l}\text { Espacios } \\
\text { verdes }\end{array}$} & Bueno-menos de $400 \mathrm{~m}$ & $0 \%$ & $29 \%$ & 0 & 0 & $36 \%$ \\
\hline & & Regular-entre 400 y $800 \mathrm{~m}$ & $33 \%$ & $23 \%$ & $40 \%$ & $50 \%$ & $36 \%$ \\
\hline & & Malo- más de 800 m & $66 \%$ & $48 \%$ & $60 \%$ & $50 \%$ & $28 \%$ \\
\hline \multirow{5}{*}{ 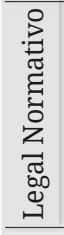 } & \multirow{3}{*}{ Área } & En área urbana & $66 \%$ & $63 \%$ & $60 \%$ & $50 \%$ & $55 \%$ \\
\hline & & En área complementaria & $0 \%$ & $29 \%$ & $40 \%$ & $25 \%$ & $36 \%$ \\
\hline & & En área rural & $33 \%$ & $8 \%$ & 0 & $25 \%$ & $9 \%$ \\
\hline & \multirow{2}{*}{ Zona-uso } & Residencial & $0 \%$ & $63 \%$ & $60 \%$ & 0 & $27 \%$ \\
\hline & & No residencial & $100 \%$ & $37 \%$ & $40 \%$ & $100 \%$ & $73 \%$ \\
\hline \multirow{3}{*}{\multicolumn{2}{|c|}{$\begin{array}{l}\text { Grado de } \\
\text { consolidación }\end{array}$}} & ALTO & $0 \%$ & $14 \%$ & $20 \%$ & $25 \%$ & $0 \%$ \\
\hline & & MEDIO & $66 \%$ & $66 \%$ & $60 \%$ & $75 \%$ & $91 \%$ \\
\hline & & BAJO & $33 \%$ & $20 \%$ & $20 \%$ & 0 & $9 \%$ \\
\hline
\end{tabular}

Fuente: elaboración propia 
programa de lotes con servicio el porcentaje es 75 (tabla 5). El acceso a establecimientos educativos resulta más crítico para los barrios de lotes individuales: el $60 \%$ no tiene acceso a una escuela a menos de $1000 \mathrm{~m}$ de su casa. En el caso de los proyectos de lotes con servicios, el 75 \% cuenta con el acceso a una escuela a menos de $1000 \mathrm{~m}$ de su casa, pero a más de $600 \mathrm{~m}$ (tabla 5). Pasando al grado de accesibilidad a espacios verdes de uso público, la mitad de los barrios tiene un mal acceso a dichos espacios de esparcimiento, un $60 \%$ en el caso de los lotes individuales y un $50 \%$ en los lotes con servicios. Por último, el análisis de la dimensión legal normativa determinó que el 60 \% de los barrios de lotes individuales se asentaron en áreas “urbanas” y el 40 \% restante lo hizo en áreas “complementarias”, aunque solo el 60 \% de los barrios se insertó en una zona de uso "residencial". Los barrios de lotes con servicios se asentaron en un $50 \%$ de los casos en áreas "urbanas”, un 25 \% en áreas “complementarias” y un 25 \% en áreas "rurales”, pero ninguno se inserto en una zona de uso "residencial” (tabla 5). Esto indica algún tipo de renovación o recuperación de terrenos en desuso por parte del Estado, o la adquisición de terrenos de privados que inicialmente no tuvieran un destino residencial.

\section{Reflexiones finales}

El análisis sobre las lógicas de ocupación residencial, tanto formales como informales, permitió profundizar la problematización del modelo de desarrollo expansivo y no planificado, presente en varias de las ciudades argentinas, así como también poner en evidencia las consecuencias de la especulación inmobiliaria sobre el mercado del suelo y sobre las políticas habitacionales que se llevaron a cabo, y continúan desarrollándose, en el partido de La Plata. El acelerado proceso de urbanización en las ciudades argentinas ha provocado el crecimiento de áreas predominantemente residenciales en las periferias urbanas, sin equipamientos o servicios al alcance de la población, lo que dio como resultado ciudades desequilibradas.

En el caso del partido de La Plata, pudo observarse en el último período intercensal un aumento del $51 \%$ del parque habitacional, frente al $13 \%$ del crecimiento de la población. Entre los años 2001 y 2010 la superficie urbana del partido creció un 57.54 \% (CIPUV, 2013), tres veces más que el crecimiento de la población. Estos dos factores indican, por un lado, una sobreproducción de vivienda en relación con la cantidad de población residente en el partido y, por otro lado, una expansión en la localización del nuevo parque habitacional. Ambos procesos son producto del efecto combinado del aumento del precio del suelo y la 
aplicación de programas nacionales de vivienda localizados en suelo sin servicios ni equipamiento, que configuran de esta forma áreas residenciales monofuncionales alejadas del equipamiento y las actividades urbanas.

Considerando la localización y el grado de consolidación urbana de las nuevas áreas donde fue asentándose la población, puede afirmarse que los barrios que surgieron en el período 2003-2012 en relación con los barrios del período 2012-2016 presentan mayoritariamente un grado de consolidación medio y tendencias similares. Por otro lado, comparando lógicas formales e informales, se puede observar que los barrios generados a partir de políticas públicas - en contraste con los asentamientos informales - tienen grados de consolidación similares, una mayoría de barrios de nivel medio (71 \%), una menor proporción de nivel bajo (17 \%) y una aún menor proporción de nivel alto (12 \%). A su vez, los barrios del Plan Federal, en contraste con los barrios del plan ProCreAr, tuvieron un menor grado de consolidación en las áreas donde se insertaron, con un $66 \%$ de los barrios con un grado medio de consolidación y un 33 \% con un bajo grado de consolidación. Los barrios ProCreAr, en cambio, tuvieron un $67 \%$ de barrios con un grado de consolidación medio, un 22 \% con un grado de consolidación alto y un 11 \% con un grado de consolidación bajo.

El análisis de la dimensión ambiental confirmó la tendencia de los asentamientos a localizarse en terrenos anegables, por ser lotes no aptos para la residencia formal. El análisis de la dimensión funcional espacial evidenció el patrón expansivo de crecimiento, según el cual los nuevos barrios, formales o informales, solo pueden asentarse en distancias que superen los $6 \mathrm{~km}$ del centro de la ciudad. Con respecto a la cobertura de la red de transporte público, la situación de la mayoría de los barrios es de una cobertura regular a buena; sin embargo, este trabajo solo consideró la cobertura física de la red, sin analizar las frecuencias o la cantidad de líneas que circulan próximas a cada barrio; esto incide significativamente en la calidad del acceso al transporte público, como bien demuestra Cola en su tesis (2019), por lo cual serían aspectos que incorporar en futuros análisis. Con respecto a la cobertura de servicios de infraestructura, la tendencia se repite para todos los períodos y barrios, con algunas excepciones particulares, una baja cobertura del servicio de red de gas y de cloacas y una buena cobertura del servicio de agua y electricidad. Esto se relaciona con los costos que implica extender la infraestructura en áreas de baja densidad poblacional, y cómo el modelo expansivo y sin planificación atenta contra la posibilidad de cubrir de manera óptima las áreas más dispersas (SAM, 2015). 
En relación con el análisis de la dimensión económico social, resulta crítico el acceso a los servicios de salud en la periferia del partido de La Plata: un $80 \%$ de los barrios carece de un centro de atención a menos de $1000 \mathrm{~m}$. El grado de accesibilidad a establecimientos educativos es regular en términos generales; sin embargo, son varias las razones que llevan a los padres a elegir una escuela para sus hijos, y la cercanía es solo una de ellas, por lo cual este indicador no implica necesariamente que todos los niños acudan a su escuela más cercana o que tengan disponibles todos los niveles de educación dentro de un mismo establecimiento (maternal, jardín, primaria, secundaria). Los espacios verdes, por otra parte, tienen una distribución variable en el territorio, y su accesibilidad se modifica según la zona; sin embargo, la calidad de espacio público presente en las áreas de la periferia de La Plata tiene un carácter precario y espontáneo, por tratarse de espacios improvisados por la propia comunidad.

El análisis de la dimensión legal normativa permitió constatar que la mayoría, entre el 50 y el 60 \% de los barrios, se localizó en áreas “urbanas”, según la designación del COU (2010). El subprograma lotes con servicios del ProCreAr presenta un caso particular, ya que el 25 $\%$ de sus casos se asentaron en áreas, hasta entonces, "rurales". Esto reconoce el conflicto que implicó el acceso al suelo en la aplicación del programa, incluso para los proyectos impulsados por los organismos públicos. Esto se corrobora cuando analizamos la zonificación de los barrios del último período 2012-2016, la gran mayoría se asentó en terrenos que por normativa eran de uso "no-residencial", lo que confirma el avance de la vivienda sobre otros tipos de uso, como productivo, de reserva o industrial.

En la actualidad, reside en la periferia platense el 70 \% de la población del partido (INDEC, 2015); sin embargo, dicho sector presenta una distribución desigual de los equipamientos urbanos y está desprovisto de un servicio de transporte público de calidad. En este sentido, se pone en evidencia la limitación en la aplicación de políticas urbanas en la ciudad de La Plata a la estructuración de algunos pocos indicadores de ocupación, sin intervenir u orientar las diferentes lógicas de ocupación del territorio. La falta de una mirada integrada sobre la planificación lleva al despliegue de políticas de carácter fuertemente económico, que, a pesar de buscar garantizar un derecho básico social como la vivienda, no contemplan el mercado de suelo en el cual esta se desarrolla y, por tanto, fomentan la especulación sobre el valor del suelo. Al mismo tiempo, pensar la vivienda como un elemento aislado del hábitat urbano lleva a la formulación de políticas que facilitan el acceso a un bien material, pero no garantizan el acceso a la ciudad (OszLaK, 1991). 


\section{Referencias bibliográficas}

ABRAMO, Pedro (2010). El mercado del suelo informal en favelas y la movilidad residencial de los pobres en las grandes metrópolis. En: Revista Territorios, (18-19), 55-73. Argentina: Editorial Universidad de Rosario.

ABRAMO, P. (2012). La ciudad com-fusa: Mercado y producción de la estructura urbana en las grandes metrópolis latinoamericanas. Revista EURE, 38, 35-69. http:// doi.org/10.4067/S0250-71612012000200002

AÓN, L. C., GIGLIO, M. L., y COLA, C. A. (2017). Patrones modales de movilidad y desarrollo urbano no planificado en la ciudad de La Plata. Revista Transporte y Territorio, 0(17), 117-144. Recuperado de: http://revistascientificas.filo. uba.ar/index.php/rtt/article/view/3870

ARAMBURU, F. y CHIARA, C. (2016). Los planes federales de vivienda en el área metropolitana de Buenos Aires. IX Jornadas de Sociología de la UNLP, 5 al 7 de diciembre de 2016, Ensenada, Argentina. En Memoria Académica. Recuperado de: http://www.memoria.fahce.unlp.edu.ar/trab_eventos/ev.9056/ ev.9056.pdf

BAER, Luis (2011). El mercado de suelo formal de la Ciudad de Buenos Aires en su contexto metropolitano (tesis de Doctorado en Geografía). Facultad de Filosofía y Letras, Universidad de Buenos Aires, Argentina.

BAER, L. y KAUW, M. (2016). Mercado inmobiliario y acceso a la vivienda formal en la Ciudad de Buenos Aires, y su contexto metropolitano, entre 2003 y 2013, 42, 5-25.

BRAIN, Isabel, y SABATINI, Francisco (2006). "Los precios del suelo en alza carcomen el subsidio habitacional, contribuyendo al deterioro en la calidad y localización de la vivienda social”. En ProUrbana, (4), 1-13. Chile: Pontificia Universidad Católica de Chile.

COLA, C. (2019) El tiempo de viaje como variable crítica para la planificación del transporte público masivo y el desarrollo urbano. Prospectivas para el Gran La Plata (tesis doctoral). Facultad de Arquitectura y Urbanismo. Universidad Nacional de La Plata. Recuperado de: http://sedici.unlp.edu.ar/handle/10915/76084

CORTIZO, D. (2018). Tierra vacante y expansión urbana. Aporte teórico metodológico para una futura intervención desde un enfoque sostenible. El caso del partido de La Plata (tesis de maestría en Ciencias del Territorio). 
Universidad Nacional De La Plata. Recuperado de: http://sedici.unlp. edu.ar/handle/10915/72414

DEL Río, Juan Pablo (2011). El lugar de la vivienda social en la ciudad: Un análisis de la política habitacional desde el mercado de localizaciones intra-urbanas y las trayectorias residenciales de los habitantes (tesis doctoral). Universidad Nacional de La Plata. Facultad de Humanidades y Ciencias de la Educación. Recuperado de: http://www.memoria.fahce.unlp.edu.ar/tesis/te.464/ te.464.pdf

DEL RíO, J. P., y RELLI, M. (2013). Concentración De La Oferta Inmobiliaria Y Nuevos Agentes En El Gran La Plata (2010), 1-20. Recuperado de: http://www.cecs-argentina.org/web2015/wp-content/uploads/2015/05/del-Rio_Relli_Mendoza_2013.pdf

DEL Río, J. P., LANGARD, F., y RELLI, M. (2014). Mercado inmobiliario y acceso a la ciudad: ¿Por qué no bajan los precios como anunció el sector inmobiliario-constructor platense. Terceras Jornadas Nacionales de Investigación y Docencia en Geografía Argentina. La Plata.

DEL RÍo, Juan Pablo (2016). Tensiones entre hipoteca, suelo y política urbana. El caso del Pro.Cre.Ar en el partido de La Plata, provincia de Buenos Aires. En: Revista Estudios Socioterritoriales, 0(19), 135-151. Argentina: Universidad Nacional del Centro de la Provincia de Buenos Aires.

FREAZA, Nadia y AÓN, Laura Cristina (2014) Una ciudad, dos modelos: Fractura del tejido urbano y social en la ciudad de La Plata. Ponencia presentada en I Congreso Latinoamericano sobre Conflictos Ambientales. Organizado por el Instituto del Conurbano, Universidad Nacional de General Sarmiento, Argentina.

FREAZA, Nadia, GIGLIO, María Luciana, y AÓN, Laura Cristina (2017). Pérdida de complejidad en la ciudad compacta del mercado inmobiliario. Diez años de crecimiento del parque habitacional y desarrollo inmobiliario en área central de La Plata. En Revista Geograficando, (13), 1-15. Departamento de Geografía, Facultad de Humanidades y Ciencias de la Educación, Universidad Nacional de La Plata, Argentina.

FREDIANI, J. C. (2006). Modelos Urbanos: La ciudad compacta y la ciudad difusa. Su análisis a través de las redes de servicios y transporte en el Partido de La Plata. Informe de Beca de Formación Superior UNLP. Recuperado de: http://www. academia.edu/download/31438042/Paper_Io_EBEC_2005_FREDIANI.pdf 
FREDIANI, Julieta Constanza (2010). La expansión residencial en áreas periurbanas del Partido de La Plata. Las modalidades expansivas formal cerrada e informal abierta. Universidad Nacional de La Plata. En Revista Proyección (9). Facultad de Humanidades y Ciencias de la Educación. Universidad Nacional de La Plata, Argentina.

JENSEN, K. (2018). Paisajes vacantes. El paisaje y los espacios verdes en la periferia platense (tesis doctoral). Facultad de Arquitectura y Urbanismo. Universidad Nacional de La Plata. Recuperado de: http://sedici.unlp.edu.ar/handle/10915/72319

LEFEBVRE, H., GONZÁLEZ-PUEYO, J., y GAVIRIA, M. (1969). El derecho a la ciudad. Recuperado de: http://www.jstor.org/stable/pdf/20795675.pdf

MORALES-SCHECHINGER, C. (2005). Políticas de suelo urbano, accesibilidad de los pobres y recuperación de plusvalías. México: Universidad Nacional Autónoma de México. Recuperado de http://www.sistemamid.com/panel/uploads/biblioteca/7097/7128/7134/83936.pdf

OSZLAK, O. (1991). Merecer la Ciudad. Los pobres y el derecho al espacio urbano. Buenos Aires: Humanitas.

PÍREZ, P. (1995). Actores sociales y gestión de la ciudad. Ciudades. Recuperado de: http://ecaths1.s3.amazonaws.com/itauncoma/748058329.Pirez Pedro actores.pdf

ROLNIK, R. (2008). Normativa urbanística y exclusión social. Revista Digital Café de Las Ciudades, 7(63). Recuperado de http://www.cafedelasciudades.com.ar/planes_63_3.htm

SABATINI, Francisco, \& SMOLKA, Martim (2002). The 1980s reforms and the access of the poor to urban land in Latin America. En J. Behar, U. Jonsson, \& M. Lundahl (Eds.), Current of change: globalization, democratization and institutional reform in Latin America (pp. 269-289). Suecia: Universidad de Estocolmo. Instituto de Estudios Latinoamericanos.

\section{Fuentes citadas}

ANSES (2015). PROCREAR. Hacia una política urbana inclusiva. (Anses, Ed.) (10). Dirección de Desarrollo de Suelo Urbano. Presidencia de la Nación.

ARBA (2014). Base cartográfica de parcelamiento urbano del Partido de La Plata. Agencia de Recaudación de la Provincia de Buenos Aires. 
CIPUV (2013). Atlas de Crecimiento Urbano. Centro de Investigación de Políticas Urbanas y de Vivienda. Universidad Don Torcuato Di Tella.

COU (2010). Código de Ordenamiento Urbano de los Partidos de La Plata. Ordenanza 10703, Reglamentada por Decreto Municipal 2418/11 y por Decreto Municipal 605/12. La Plata.

INDEC (2001). Censo Nacional de Población, Hogares y Viviendas del año 2001- La Plata, Berisso y Ensenada.

INDEC (2010). Censo Nacional de Población, Hogares y Viviendas 2010 -La Plata, Berisso y Ensenada.

INDEC (2015). Proyecciones de población por sexo y edad del período 2010-2040 -La Plata, Berisso y Ensenada.

JENSEN, K. y BIRCHE, M. (2017). Relevamiento de espacios verdes de uso público. Disponible en Anexo 3, tesis doctoral Jensen (2018).

LÓPEZ, M. J. (2016). Cartografía Escuelas Partido de La Plata. Construcción sobre la base de datos del Ministerio de Educación de la Provincia de Buenos Aires, Parcelario ARBA año 2015 e imágenes Google Earth-Google Street View año 2016. Propiedad personal.

OPORTO, G., AGUILAR, M., y BLANCO, J. (2011). Plan Estratégico Territorial Avance II: Argentina Urbana. (Disegnobrass, Ed.) (1º). Buenos Aires: Subsecretaría de Planificación Territorial de la Inversión Pública, Ministerio de Planificación Federal, Inversión Pública y Servicios. Recuperado de: https://dl.dropboxusercontent.com/u/14646967/PET2011_Lib3\%20Cap2.pdf

SAM (2015). Financiamiento de Infraestructura Urbana. Criterios para un modelo de gestión público-privado. Secretaría de Asuntos Municipales. Buenos Aires.

SIISA (2018). Registro Federal de Establecimientos de Salud Públicos y Privados. Sistema integrado de información sanitaria argentino.

SSTUyV (2015). Registro Provincial Público de Villas y Asentamientos Precarios. Subsecretaría Social de Tierras, Urbanismo y Vivienda. Ministerio de Infraestructura y Servicios Públicos de la Provincia de Buenos Aires. Recuperado de: http://www.mosp.gba.gov.ar/subsecretarias/reg_vilyasent.php

UNLP (2017) Las inundaciones en La Plata, Berisso y Ensenada: análisis de riesgo, estrategias de intervención. Hacia la construcción de un observatorio ambiental. Informe Final Proyecto de Investigación Orientado (PIO) CONICET-UNLP (2014-2016). Anexo 1.A. Cartografía temática. Recuperado de: http://sedici. unlp.edu.ar/handle/10915/59633. 